\title{
Distinct Impacts of Aerosols on an Evolving Continental Cloud Complex during the RACORO Field Campaign ${ }^{O}$
}

\author{
YUN LIN \\ Texas A\&M University, College Station, Texas \\ YUAN WANG \\ Jet Propulsion Laboratory, California Institute of Technology, Pasadena, California \\ BOWEN PAN AND JIAXI HU \\ Texas A\&M University, College Station, Texas \\ YANGANG LIU \\ Brookhaven National Laboratory, Upton, New York \\ RENYI ZHANG \\ Texas A\&M University, College Station, Texas
}

(Manuscript received 7 December 2015, in final form 19 May 2016)

\begin{abstract}
A continental cloud complex, consisting of shallow cumuli, a deep convective cloud (DCC), and stratus, is simulated by a cloud-resolving Weather Research and Forecasting Model to investigate the aerosol microphysical effect (AME) and aerosol radiative effect (ARE) on the various cloud regimes and their transitions during the Department of Energy Routine Atmospheric Radiation Measurement Aerial Facility Clouds with Low Optical Water Depths Optical Radiative Observations (RACORO) campaign. Under an elevated aerosol loading with AME only, a reduced cloudiness for the shallow cumuli and stratus resulted from more droplet evaporation competing with suppressed precipitation, but an enhanced cloudiness for the DCC is attributed to more condensation. With the inclusion of ARE, the shallow cumuli are suppressed owing to the thermodynamic effects of light-absorbing aerosols. The responses of DCC and stratus to aerosols are monotonic with AME only but nonmonotonic with both AME and ARE. The DCC is invigorated because of favorable convection and moisture conditions at night induced by daytime ARE, via the so-called aerosol-enhanced conditional instability mechanism. The results reveal that the overall aerosol effects on the cloud complex are distinct from the individual cloud types, highlighting that the aerosol-cloud interactions for diverse cloud regimes and their transitions need to be evaluated to assess the regional and global climatic impacts.
\end{abstract}

\section{Introduction}

By acting as cloud condensation nuclei $(\mathrm{CCN})$ and ice nuclei, atmospheric aerosols affect cloud and precipitation processes, referred to as the aerosol microphysical

Supplemental information related to this paper is available at the Journals Online website: http://dx.doi.org/10.1175/ JAS-D-15-0361.s1.

Corresponding author address: Renyi Zhang, Department of Atmospheric Sciences, Texas A\&M University, Oceanography and Meteorology Building, Room 1108, MS 3150, College Station, TX 77843. E-mail: renyi-zhang@tamu.edu effect (AME) (Twomey 1977; Zhang et al. 2007; DeMott et al. 2011; Tao and Matsui 2015). Aerosols also alter the earth radiative budget by scattering and absorbing shortwave and longwave radiation (Charlson and Pilat 1969; Coakley et al. 1983; Peng et al. 2016), referred to as the aerosol direct effect, which in turn modifies the atmospheric temperature structure and cloud lifetime (Hansen et al. 1997; Ackerman et al. 2000; Wang et al. 2013b), referred to as the aerosol semidirect effect. The aerosol direct and semidirect effects commonly are considered together as the aerosol radiative effects (ARE). Currently, the understanding of the aerosol effects on weather and climate remain uncertain, since 
representation of the aerosol and cloud processes, particularly the subgrid cloud dynamics and feedback, by atmospheric numerical models is still difficult, leading to the largest uncertainty in climate projections (IPCC 2013; Wu et al. 2016).

The responses of clouds and precipitation to variable aerosol loadings are complicated, depending on the aerosol properties, cloud systems, and environmental conditions (Yuan et al. 2008; Khain 2009; Lee et al. 2009; Li et al. 2011). Several previous studies (Khain et al. 2005; Seifert and Beheng 2006; Tao et al. 2007; Khain et al. 2008; Lee et al. 2010; Storer et al. 2010; Li et al. 2011; Small et al. 2011) have indicated that aerosol-cloud interactions differ among cloud types and regimes. For example, shallow cumulus and marine stratocumulus have been demonstrated to be sensitive to AME (Kaufman et al. 2005; Matsui et al. 2006; Xue et al. 2008; Kogan et al. 2012; Yang et al. 2012; Werner et al. 2014), since an increased aerosol concentration leads to a smaller effective droplet radius, a higher droplet concentration, lesser precipitation, a higher cloud liquid water, longer-lived clouds, and a larger cloud fraction. However, a number of other studies of shallow cumulus have indicated that the cloud fraction and lifetime are not necessarily enhanced under more polluted conditions (Wang et al. 2003; Jiang and Feingold 2006; Lin et al. 2006; Small et al. 2009; Seigel 2014; Saleeby et al. 2015). Deep convective clouds (DCCs) are also affected by AME. For example, a higher aerosol loading leads to a suppressed warm rain process but enhanced mixedphased processes (Andreae et al. 2004; Khain et al. 2005; van den Heever et al. 2006; Li et al. 2008b). The modifications on DCC microphysical processes by aerosols are attributed to the enhancements of liquid water mass loading and additional latent heat released, leading to invigorated convection ( $\mathrm{Li}$ et al. 2008a; Li et al. 2008b; Tao et al. 2012), or to an increasing amount of long-lasting small ice particles in stratiform/anvils, as recently suggested by Fan et al. (2013). Conflicting results have been reported for the aerosol impacts on precipitation in different deep convective systems (Khain et al. 2005; Tao et al. 2007; Wang et al. 2011; Lee and Feingold 2013), and those previous studies have demonstrated that the correlation between AME and aerosols is highly variable, dependent on the scale and types of clouds and meteorological environments (Tao et al. 2007; Khain et al. 2008; Jiang et al. 2011).

Progress has also been made to elucidate the aerosol-cloud-radiation feedback on regional and global scales (Tie et al. 2003). Several studies have revealed that a reduced cloud cover, lowered cloud optical thickness, or a short cloud lifetime occurs for low- and midlevel clouds with absorbing aerosols (Johnson et al. 2004; Zhang et al. 2008; Allen and Sherwood 2010; Sakaeda et al. 2011; Li et al. 2013). Fan et al. (2008) have shown that ARE induces a decrease in relative humidity, resulting in a decreased cloud cover and optical depth and suppressed precipitation for a daytime DCC. A study of ARE on sea breezes by Grant and van den Heever (2014) has shown that aerosols suppress the precipitation due to reducing downwelling shortwave radiation and surface latent heat fluxes. The aerosol semidirect effect is dependent on the locations of an aerosol layer relative to the clouds and underlying surface (Lindeman et al. 2011; Wang et al. 2013b). For the case that aerosols lay above a cloud layer, particularly for marine stratocumulus cloud decks over the regions off the western coasts of continents, the diabatic heating due to aerosol absorption strengthens the inversion and reduces the entrainment rate, causing an enhancement of stratocumulus clouds (Wilcox 2010; Sakaeda et al. 2011; Li et al. 2013; Yamaguchi et al. 2015).

Realistic simulations of the various cloud systems are crucial to reduce the uncertainty in quantitative assessment of the aerosol effects on climate (IPCC 2013). Although the previous studies have examined the aerosol effects on isolated continental DCCs (Fan et al. 2007a, 2008; Li et al. 2008b), the continental cloud system consisting of various boundary layer cloud regions has not been properly represented in current atmospheric models because of poorly parameterized small-scale turbulence and convection (Zhang et al. 2005; Vogelmann et al. 2012; Wood 2012). To evaluate the properties of such continental boundary layer clouds and their association with aerosols, a field campaign, Routine ARM Aerial Facility (AAF) Clouds with Low Optical Water Depths (CLOWD) Optical Radiative Observations (RACORO) organized by DOE has been conducted at the ARM Southern Great Plains (SGP) site (Vogelmann et al. 2012). The five-month campaign provides a first extended-term airborne and ground-based cloud and aerosol information for various continental boundary layer clouds. The RACORO campaign has already been examined by some parameterization studies (Lu et al. 2013). However, detailed studies on AME and ARE from the RACORO continental cloud systems are still lacking. In addition, most of the previous studies have focused on either AME or ARE (Johnson et al. 2004; Lee and Feingold 2013), and only a few studies 
(e.g., Fan et al. 2008; Shi et al. 2014; Jiang and Feingold 2006) have been specifically designed to simultaneously examine the overall aerosol effects at the cloud-resolving scale, including aerosol direct, semidirect, and indirect effects, particularly for the continental boundary layer clouds. Shi et al. (2014) have simultaneously tested AME and ARE on continental convective clouds over West Africa and found that ARE dominantly modulates the dynamics of convective clouds. Moreover, the recent IPCC report (IPCC 2013) and other previous studies (e.g., Li et al. 2011; Fan et al. 2013) have indicated that the investigation of long-term aerosol net effects on different cloud types are critical because the aerosol effects are likely different for the different cloud regimes.

In this paper, we present a systematic modeling study of the aerosol impacts on a continental cloud complex during the RACORO field campaign, in which three different sequentially appearing continental cloud regimes are identified. Simulations using the WRF Model are performed and compared with the RACORO field measurements. Sensitivity studies with and without ARE are conducted to examine the responses of clouds and precipitation to aerosol loadings and thus provide a comprehensive view on the interactions between aerosols and continental clouds. In particular, the aerosol net effects on the cloud complex are evaluated to assess the overall response of the various cloud regimes. Although the selected case in our study is limited in representation of the various cloud systems over a long period, this modeling work separately evaluates both aerosol microphysics and radiative effects on the evolution of a cloud complex with three important cloud regimes. Our results provide insights into the role of aerosols in the development of a complicated cloud system, including the net aerosol effects.

\section{Experiment setup}

\section{a. Case description}

The evolving continental cloud complex over the SGP region spanned from 25 to 27 May 2009, including shallow cumuli, a DCC, and 1-day persisting stratus. On 25 May, the shallow cumuli formed by weak and isolated convection and lasted for a few hours (0900-1800 LST) with small-scale drizzle precipitation at the dissipation stage. From 1700 LST 25 May to 0900 LST 27 May, a large-scale cold front passed across the SGP region, stretching from the low pressure center in South Dakota to the southwest end in the Texas Panhandle (see Fig. S1 in the online supplementary material). A strong prefrontal convective line passed the ARM site observational area in the early morning of 26 May (from 0000 to 0600 LST) associated with the formation of DCC, which caused intensive precipitation. During and after the cold front passage at the SGP site, weakly precipitating stratus developed at 2100 LST 26 May and persisted throughout 27 May, with relatively thick cloud physical and optical depths.

\section{b. Model configuration}

A Weather Research and Forecasting Model, version 3.1.1, with an aerosol-aware two-moment bulk microphysics scheme developed by Li et al. (2008b) at Texas A\&M University (TAMU-WRF) is employed in this study. TAMU-WRF has been successfully used for investigations of AME on cloud, precipitation, or lightning activities in isolated convective storms and mesoscale convective systems ( $\mathrm{Li}$ et al. 2009; Wang et al. 2011, 2013a, 2014a,b). The microphysics scheme has been described in Li et al. (2008b), in which the number concentrations of aerosols and cloud droplets are prognostically treated. This prognostic treatment is in contrast to the diagnostic feature commonly adopted in many other two-moment bulk microphysics schemes (Wang et al. 2011). Aerosols activated to form cloud droplets are assumed to contain ammonium sulfate only for AME, since ammonium sulfate represents one of the abundant aerosol chemical compositions at various continental locations (Fan et al. 2005; Zhang et al. 2015). Also, although organics, formed from photochemical oxidation of biogenic and anthropogenic volatile organic compounds (Lei et al. 2000; Zhang et al. 2002; Zhao et al. 2005), constitute the other key ingredient in aerosols, the aerosol hygroscopicity is dominated by the inorganic fraction (Guo et al. 2014). Nucleation scavenging is the only mechanism to remove aerosols in our scheme, and aerosol regeneration from droplet evaporation is not considered. Under favorable wind conditions, aerosols with a fixed number and mass concentration at the lateral boundaries of the outer domain are transported through advection and convection to provide an additional aerosol source for the inner domain. The heterogeneous ice nucleation and homogeneous freezing processes are explicitly parameterized in this microphysics scheme. The deposition nucleation parameterization is based on Pruppacher and Klett (1996), and the immersion-freezing parameterization follows Bigg (1953). The homogeneous freezing is parameterized following Milbrandt and Yau (2005). The Rapid Radiative Transfer Model (RRTM) scheme (Mlawer et al. 1997) and the Goddard scheme (Chou and Suarez 1999) are employed as the longwave and 


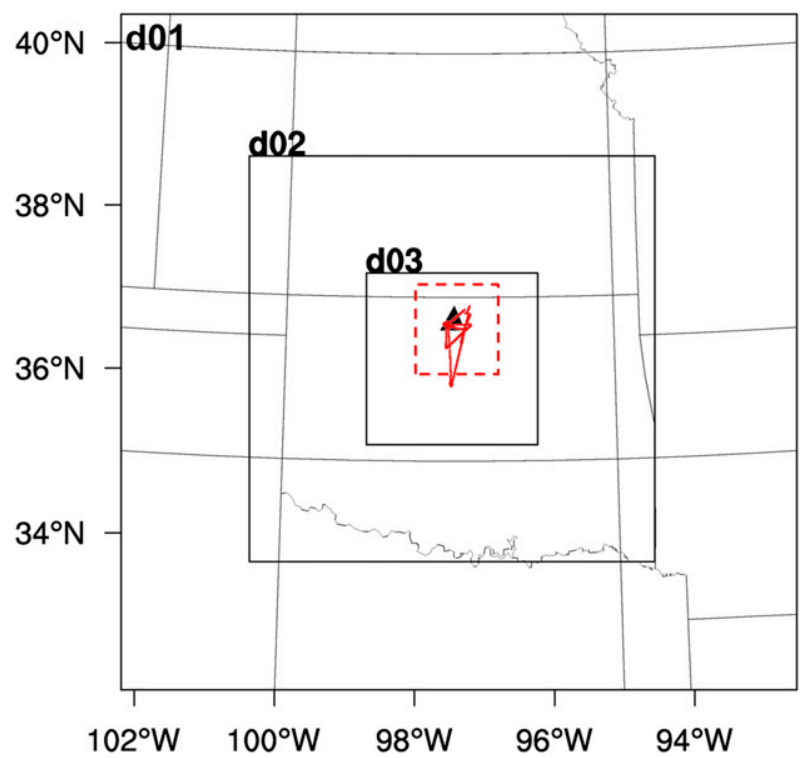

FIG. 1. Two-way nested configuration of the modeling domains. Domain $1(\mathrm{~d} 01)$ has a size of $900 \mathrm{~km} \times 900 \mathrm{~km}$ with a horizontal grid spacing of $9 \mathrm{~km}$, centered at the SGP central facility $\left(36.5934^{\circ} \mathrm{N}, 97.5113^{\circ} \mathrm{W}\right)$. Domain $2(\mathrm{~d} 02)$ has a size of $540 \mathrm{~km} \times$ $540 \mathrm{~km}$ with a horizontal grid spacing of $3 \mathrm{~km}$. Domain 3 (d03) has a size of $228 \mathrm{~km} \times 228 \mathrm{~km}$ with a horizontal grid spacing of $0.75 \mathrm{~km}$. The domain for analysis is denoted by the red dashed square with a size of $105 \mathrm{~km} \times 105 \mathrm{~km}$. The black triangle denotes the SGP site, and the red line represents the flight routines of aircraft measurements from 1200 to 1600 LST 27 May.

shortwave radiation parameterizations, respectively. The YSU scheme (Hong et al. 2006) and the thermal diffusion scheme are adopted for the planetary boundary layer parameterization and for the land surface, and no cumulus parameterization is considered. ARE is separately considered by modifying the Goddard radiation scheme to calculate aerosol optical properties (Fan et al. 2008). An internal aerosol mixture with a mass combination of $95 \%$ ammonium sulfate and $5 \%$ black carbon is assumed when calculating the aerosol radiative properties, consistent with observations (Levy et al. 2013) and other model studies (Wang et al. 2014c). More detailed description about the microphysics scheme and the modified Goddard scheme is provided in the supplemental material.

The model domain is configured with three two-way nested grids, as shown in Fig. 1. The outmost domain has a size of $900 \mathrm{~km} \times 900 \mathrm{~km}$ with a horizontal grid spacing of $9 \mathrm{~km}$, centered at the SGP central facility $\left(36.5934^{\circ} \mathrm{N}\right.$, $97.5113^{\circ} \mathrm{W}$ ). The size and horizontal grid spacings are $540 \mathrm{~km} \times 540 \mathrm{~km}$ and $3 \mathrm{~km}$ for the second domain and $228 \mathrm{~km} \times 228 \mathrm{~km}$ and $0.75 \mathrm{~km}$ for the innermost domain, respectively. Unless stated otherwise, a domain inside the innermost domain with a size of $105 \mathrm{~km} \times 105 \mathrm{~km}$ around the SGP site is used for analysis throughout this paper (Fig. 1) in order to minimize the interference from coexisting cloud regimes at the same time period and covers the flight routes during the RACORO campaign. The vertical coverage is $20 \mathrm{~km}$, consisting of 50 vertical levels with a stretched vertical resolution, which is finer close to the ground (about $50 \mathrm{~m}$ ) and coarser aloft (about $400 \mathrm{~m}$ above $14 \mathrm{~km}$ ). North American Regional Reanalysis (NARR) is used as the initial conditions and lateral boundary conditions, which are updated every $3 \mathrm{~h}$.

Sensitivity experiments are conducted to evaluate the aerosol impacts on cloud and precipitation processes. Three different aerosol scenarios are considered to reflect the range of aerosol conditions during the RACORO field campaign in 2009: a run with a clean aerosol condition (Clean), a run with the moderate aerosol level close to the measurements (Mode), and a run with the polluted condition (Pollu), with the initial surface aerosol concentrations of 280, 700, and $2800 \mathrm{~cm}^{-3}$, respectively. As shown in Fig. S2, the initial aerosol vertical profiles below $2 \mathrm{~km}$ are constrained by the airborne Passive Cavity Aerosol Spectrometer Probe (PCASP) measurements collected on 26 and 27 May 2009 during the RACORO field campaign since PCASP contains most aerosols responsible for cloud droplet formation under weak turbulence (Vogelmann et al. 2012). An approximately exponentially decreasing dependence is employed to represent the aerosol profiles with height above $2 \mathrm{~km}$ (Fan et al. 2007b; Li et al. 2009). Two simulations for each aerosol scenario are conducted-that is, with AME only and with both aerosol microphysics and aerosol radiative effects (MRE). ARE is evaluated from the differences between the MRE and AME simulations. Considering that the underlying microphysics-dynamics-thermodynamics interactions of the system are nonlinear, the differences between MRE and AME for the DCC and stratus are not solely attributable to ARE but also to the cloudenvironment interactions before the DCC or stratus. To separate ARE from the impacts of development of preceding clouds on the condition prior to later clouds, we perform additional simulations with the inclusion of microphysical (AME) and radiative (ARE) effects only (defined as MRO), in which ARE is included starting on the second day (the deep convection regime onward) and then only on the third day (the stratus regime only).

\section{Results and discussion}

\section{a. Model evaluation}

To validate our model performance, the AME and MRE simulations conducted for the moderate pollution 

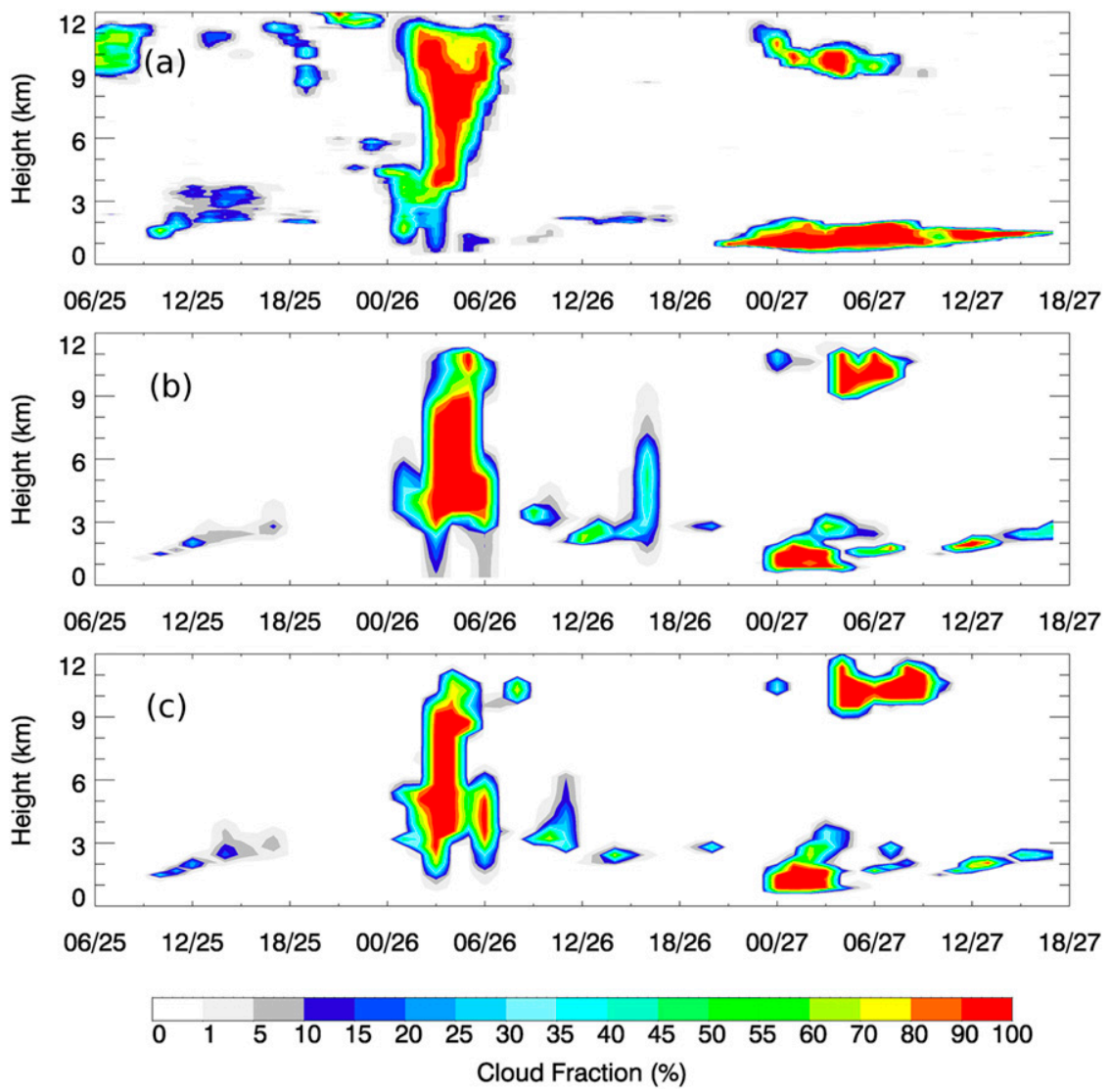

FIG. 2. Comparison of the cloud fraction profiles between observation and simulations: (a) ARSCL measurements, (b) Mode_AME run, and (c) Mode_MRE run. The shallow cumuli on 25 May, a deep convective cloud on 26 May, and a stratus on 27 May are detected and simulated.

scenario are compared with the observations from the RACORO campaign. The comparison between the ground-based measurements of $\mathrm{CCN}$ from the ARM Aerosol Observing System (AOS) and simulations shows that our simulations generally capture the temporal variation of the observed CCN (Fig. S7d). The observed cloud fraction is obtained from the ARM Active RemotelySensed Cloud Locations (ARSCL) Value-Added product. The cloud fraction from the simulations is defined as the percentage of the grids with a total hydrometeor water mass mixing ratio greater than $10^{-6} \mathrm{~kg} \mathrm{~kg}^{-1}$ within a region of $10 \mathrm{~km} \times 10 \mathrm{~km}$ centered at the SGP site. Figure 2 and Fig. S7a depict the temporal evolutions of the observed and simulated cloud fraction during 25-27 May, showing that both the AME and MRE runs reproduce the major characteristics of the different clouds and the transition of the cloud types in terms of the cloud onset time, duration, and size, although the modeled stratus is rather discontinuous. Figure S7a also shows that the simulated cloud fraction is underestimated for shallow cumuli, and the simulated stratus dissipates earlier than that of the observation. The simulated maximum radar reflectivity in a vertical column is compared with the radar measurements for the precipitation peak time period (Fig. S5), showing that the northwest-southeast-orientated distribution is captured in the simulations while the cold front passes across the SGP region.

The LWP measured by the microwave radiometer (MWR) with a uncertainty of $20-30 \mathrm{~g} \mathrm{~m}^{-2}$ over various atmospheric conditions (Turner et al. 2007) and the precipitation rate estimated by Arkansas-Red Basin River Forecast Center (ABRFC) are also used for model evaluation. The simulations reproduce the temporal variations of the LWP and precipitation rate from the observations (Figs. S7b and S7c). Figure S7b also shows that the modeled LWP for the stratus is on average one-fourth of the observed value, and Fig. S7c shows that the maximal precipitation rates from the simulations are one-half of the observed value.

The liquid water content (LWC), cloud droplet effective radius, and droplet number concentration are measured by the Cloud and Aerosol Spectrometer (CAS) 
(a) Shallow cumuli

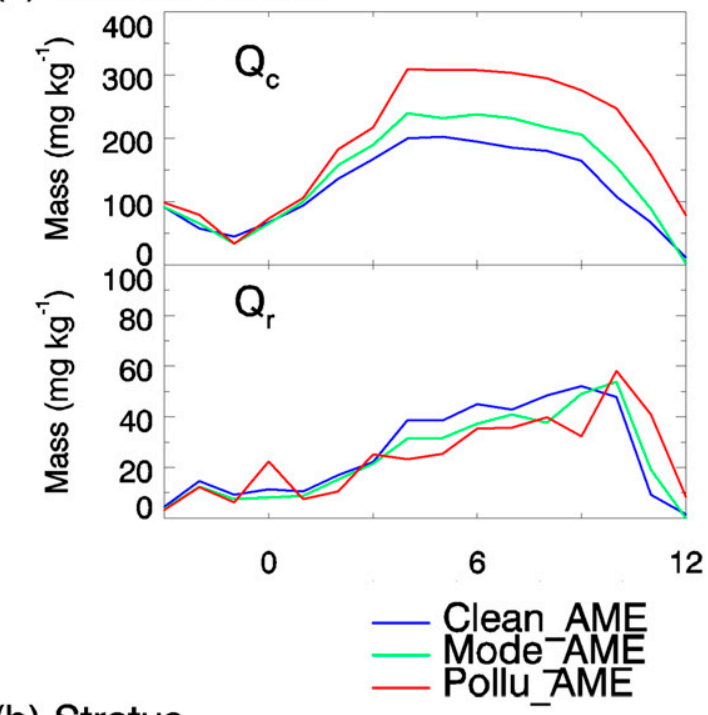

(b) Stratus

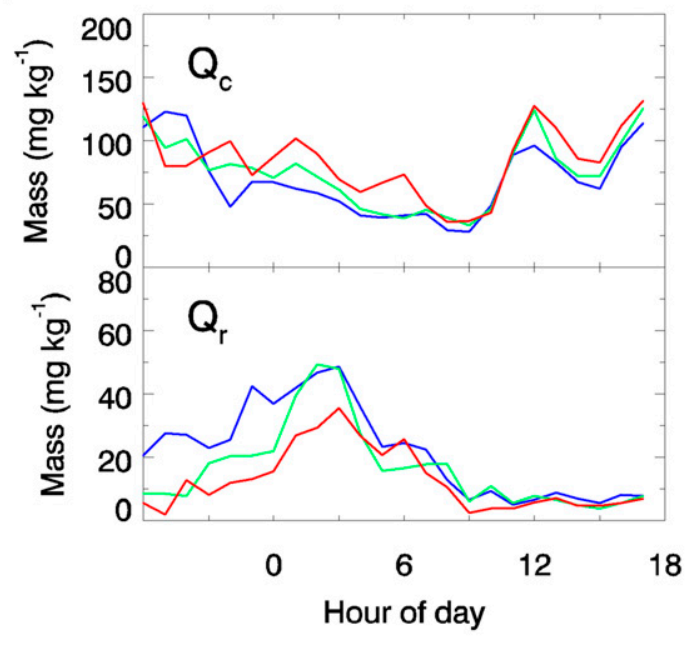

(c) DCC
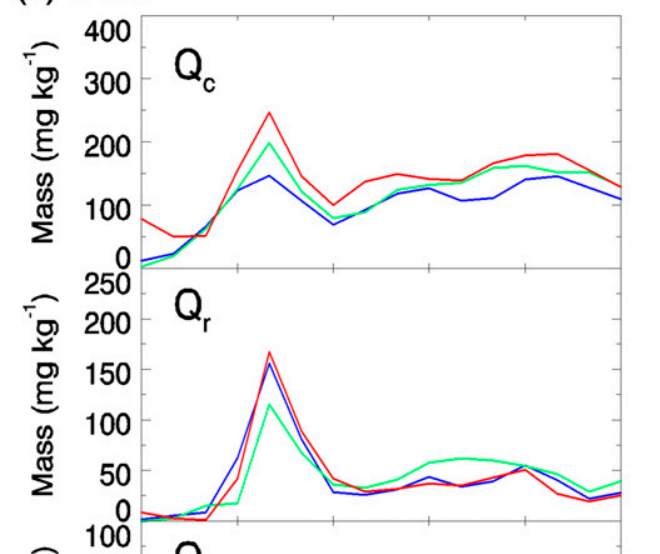

0
$\frac{1}{8}$
0
है
0
$\frac{\pi}{2}$

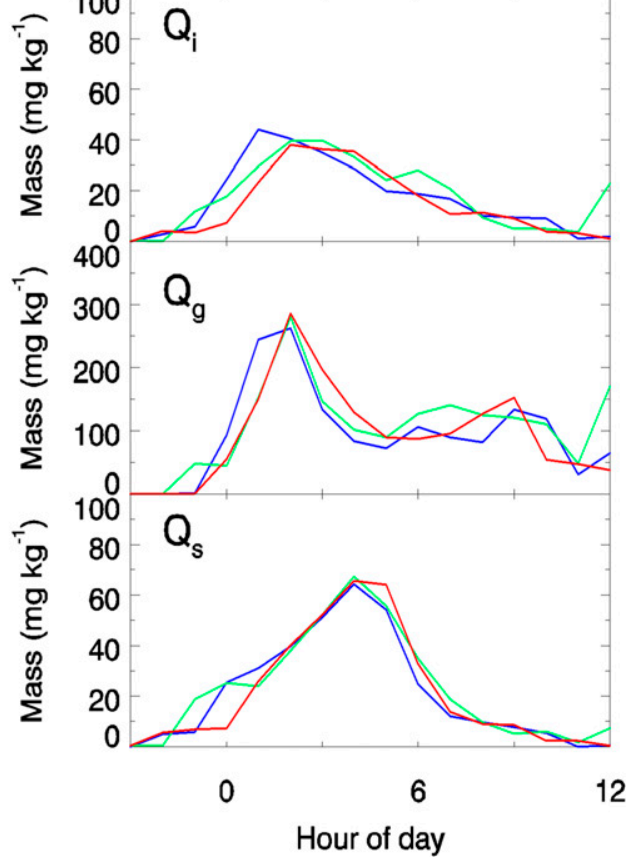

FIG. 3. Temporal evolutions of the mass mixing ratio of hydrometeors for (a) shallow cumuli, (b) stratus, and (c) DCC under three aerosol cases: Clean_AME (blue), Mode_AME (green), and Pollu_AME (red). For shallow cumuli and stratus, only cloud $Q_{c}$ and rainwater $Q_{r}$ are presented. In addition to cloud and rainwater, ice crystal $Q_{i}$, graupel $Q_{g}$, and snow $Q_{s}$ are also shown for DCC.

for a drop size distribution of $2-50 \mu \mathrm{m}$ during the aircraft flight from 1200 to 1600 LST 27 May 2009. The corresponding cloud quantities from the simulations are averaged over the time period of the aircraft flights and over all the cloud grids in the domain. A scaling factor is used to obtain the simulated cloud droplet effective radius from the volume mean radius since the cloud droplet effective radius is proportional to the volume mean radius according to Liu and Daum (2002). The domain means of the simulated LWC, cloud droplet effective radius, and number concentration exhibit similar vertical variations with the observations but the cloud droplet number concentration is about one-third of the corresponding airborne measured value (Fig. S6). The discrepancy in the cloud droplet number concentrations between model and observation may be explained because of inefficient transport of aerosols into the cloud layer by the model.

Additional simulations are conducted to examine the influence of the horizontal grid spacing in resolving the boundary layer clouds by nesting down the current horizontal grid spacing $(750 \mathrm{~m})$ to the large-eddy simulation (LES) scale $(150 \mathrm{~m})$. The simulations using both resolutions yield similar aerosol-cloud interactions (Fig. S4). In addition, the droplet nucleation rate based on an explicit supersaturation in our microphysical scheme produces a similar vertical varying pattern as the one with a parameterized turbulence (Ghan et al. 1997; 
Shallow cumuli
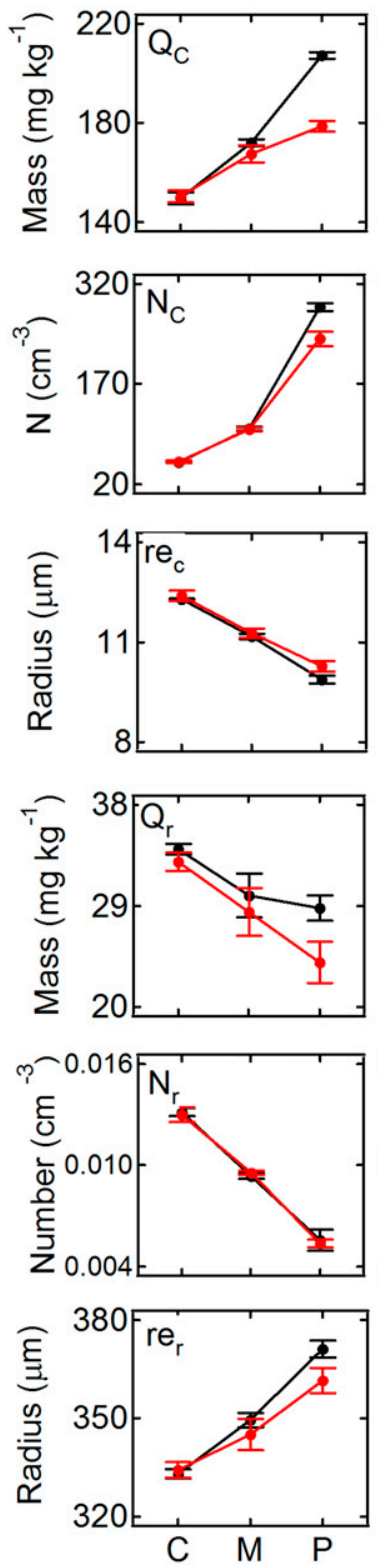

$\mathrm{DCC}(\mathrm{c}+\mathrm{r})$
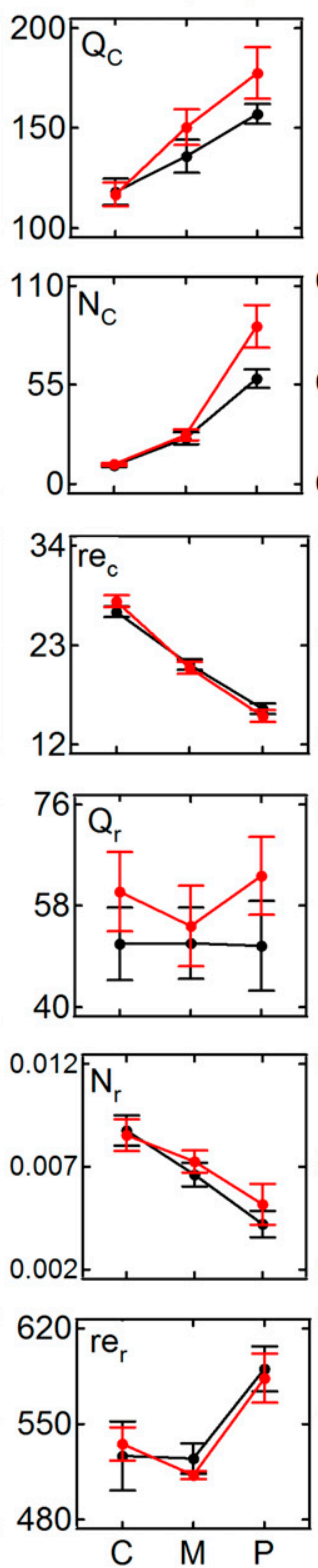

$\mathrm{DCC}(\mathrm{i}+\mathrm{g})$
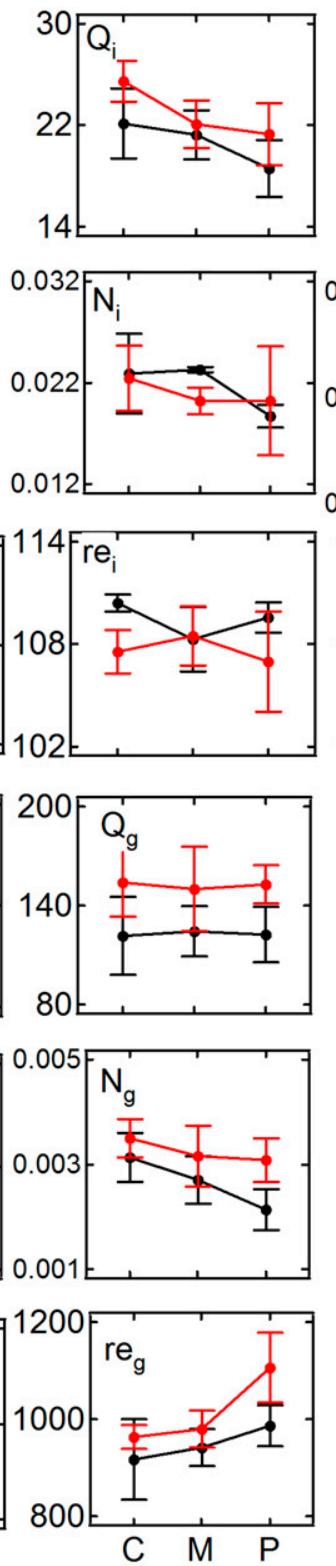

DCC (s)
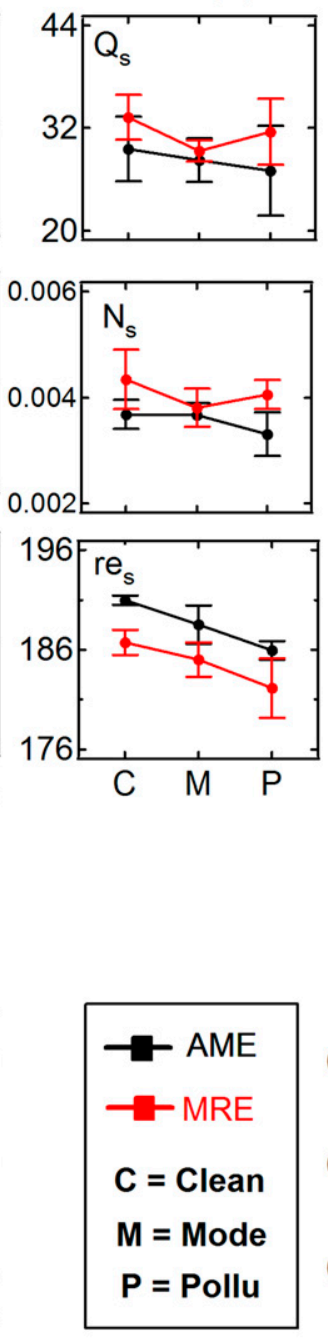
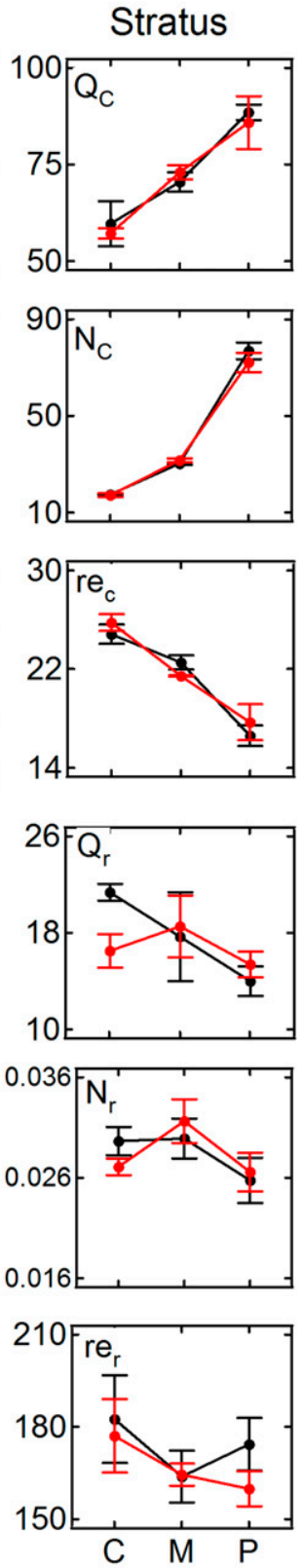

FIG. 4. Population mean of the cloud microphysical properties (cloud water mass mixing ratio $Q_{c}$; cloud droplet number concentration $N_{c}$; cloud droplet effective radius re ${ }_{c}$; rainwater mass mixing ratio $Q_{r}$; raindrop number concentration $N_{r} ;$ raindrop effective radius re $r$; ice water mass mixing ratio $Q_{i}$; ice crystal number concentration $N_{i}$; ice crystal effective radius re $;$; graupel water mass mixing ratio $Q_{g}$; graupel number concentration $N_{g}$; graupel effective radius re ${ }_{g}$; snow water mass mixing ratio $Q_{s}$; snow number concentration $N_{s}$; snow effective radius $\mathrm{re}_{s}$ ) under the Clean, Mode, and Pollu aerosol scenarios for the (left)-(right) shallow cumuli, DCC, and stratus. The black and red lines are for the AME and MRE runs, respectively. The vertical lines denote the error bars (one standard deviation), which are estimated from three ensembles conducted with small perturbations in initial temperature condition.

Abdul-Razzak et al. 1998) (Fig. S3), as discussed in the supplemental material.

\section{b. Cloud microphysics response to aerosol}

Figures 3 and 4 show the simulated cloud microphysical quantities, including the mass mixing ratio, number concentration, and effective radius of the five types of hydrometeors (i.e., cloud droplet, raindrop, ice crystal, snow, and graupel). These quantities are population means over all the selected cloudy grids (i.e., with a mass content greater than $10^{-6} \mathrm{~kg} \mathrm{~kg}^{-1}$ ) in the selected domain and averaged vertically and/or 
temporally, similarly to Fan et al. (2007b). The time periods used for the population means in Fig. 4 are 09001800 CST 25 May 2009 for shallow cumuli, 0000-0900 CST 26 May 2009 for the DCC, and 2100 CST 26 May1800 CST 27 May 2009 for the stratus. (The error bars in Figs. 4 and 6-8 represent one standard deviation, which is estimated from the means of three ensemble runs.) The ensembles are conducted with small perturbations in the initial temperature condition. Additionally, the statistical significance is evaluated for the differences induced by AME and ARE using the Student's $t$ test. For example, to determine whether the mean of a quantity of the Pollu_AME run is statistically different from that of the Clean_AME run, a $t$ test for the three ensemble means from the Clean_AME run and the Pollu_AME run is performed at a significance level of $5 \%$. Unless stated otherwise, all the enhancements or reductions due to $\mathrm{AME}$ and $\mathrm{ARE}$ reported here are statistically significant with a confidence level of $95 \%$.

Figures $3 \mathrm{a}$ and 4 show the responses of cloud droplets and raindrops to aerosols for the shallow cumuli. With AME only, the cloud droplets and raindrops exhibit monotonic changes with varying aerosol amounts. For example, the cloud water mass and droplet number increase by $47 \%$ and $500 \%$, respectively, from the Clean to Pollu run. In contrast, the rainwater mass and raindrop number decrease by $17 \%$ and $58 \%$, respectively. More efficient condensation of water vapor on activated aerosols is partially responsible for the larger cloud water mass at the higher aerosol level, since the condensation rate of water vapor depends on the cloud droplets number (Li et al. 2008b). Because of smaller cloud droplets under the polluted condition, the conversion from cloud droplets to raindrops via the collision-coalescence process is efficiently inhibited, as reflected by the lower number of raindrops in the Pollu run (Fig. 4). Once formed, raindrops grow more efficiently in the polluted environment because there is more cloud water to collect, explaining why the Pollu run produces a larger mean effective radius of raindrops $(371 \mu \mathrm{m})$ than that by the Clean run $(333 \mu \mathrm{m})$. The more efficient growth of raindrops under more polluted condition is consistent with the previous studies (Saleeby et al. 2010). AME-induced changes for the shallow cumuli are statistically significant with a confidence level of $95 \%$. For MRE runs with ARE, it is evident that at a given aerosol level both the cloud water mass and rainwater mass are reduced relative to AME simulations, implying suppressed shallow cumuli by ARE. The ARE-induced suppression of the shallow cumuli is statistically significant at $95 \%$ under the polluted condition (Pollu runs).

Figure $3 \mathrm{c}$ and Fig. 4 (the middle three columns) exhibit the dependence of DCC microphysics on aerosol loadings. With AME only, the raindrop mass mixing ratio of the DCC is insensitive to the aerosol concentration, distinct from the shallow cumuli. In our microphysics scheme, graupel below the freezing level are assumed to be completely melted ( $\mathrm{Li}$ et al. 2008b), producing additional rainwater to compensate the loss due to the inhibited collision-coalescence process in the polluted DCC. The time series in Fig. 3c shows that the amount of ice-phase hydrometeors (i.e., ice, snow, and graupel) decreases initially but later increases with aerosol amount, suggesting a delay and a temporal shift in the ice-phase processes due to AME. This temporal shift explains the overall weak dependence of ice particles on aerosols shown in Fig. 4. The fact that ice particles are insensitive to aerosols for DCC in our study is different from the previous studies, which show invigorated mixed-phase processes in polluted DCCs associated with enhanced lightning activities-that is, more aerosols lead to higher levels of ice particles (Williams et al. 1991; Nesbitt et al. 2000; Orville et al. 2001; Bond et al. 2002; Li et al. 2009; Tao et al. 2012). The minimal ice production in most polluted DCC suggests an inefficient ice nucleation. Immersion freezing is suppressed under the polluted condition, since immersion freezing is a function of the droplet size, which is smaller at a higher aerosol level (Pruppacher and Klett 1996). The inhibited ice nucleation leads to less formation of snow particles. One important mechanism to produce graupel is freezing of rain drops that are delivered to high altitudes ( $\mathrm{Li}$ et al. 2008b), as is demonstrated by the trends of graupel mass, number, and effective radius, which are similar to the corresponding rain trends in the DCC regime (Fig. 4). The amount of hydrometeors is enhanced with ARE (see MRE runs in Figs. 3c and 4), suggesting an invigoration of the DCC by ARE. For example, the graupel mass is enhanced by $28 \%$ on average in MRE runs relative to AME runs.

Figures $3 \mathrm{~b}$ and 4 (the fourth column) indicate that the microphysical response of cloud droplets in the stratus is similar to those of the shallow cumuli and the DCC. There is a monotonic decrease for raindrop mass and number in AME runs but a nonmonotonic trend in MRE runs, suggesting that ARE has noticeable influence on stratus rainwater.

\section{c. Cloud macrophysics and precipitation response to aerosol}

Figures 5 and 6 display the dependences of cloud macrophysics on initial aerosol concentrations for the different cloud regimes. In AME runs, an increase in aerosol loading leads to a reduced domain-averaged cloud fraction of the shallow cumuli and stratus but an 
(a) CF shallow cumuli
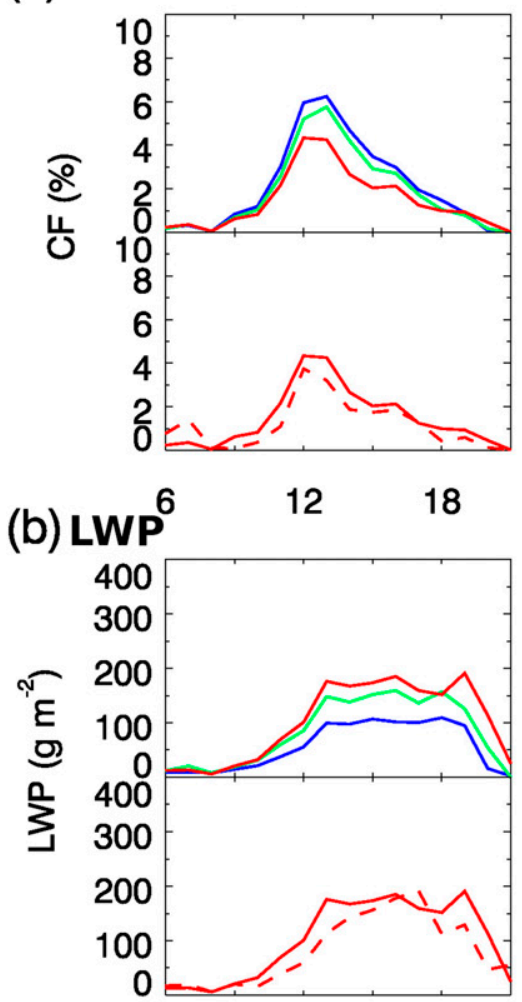

(c) Rain rate

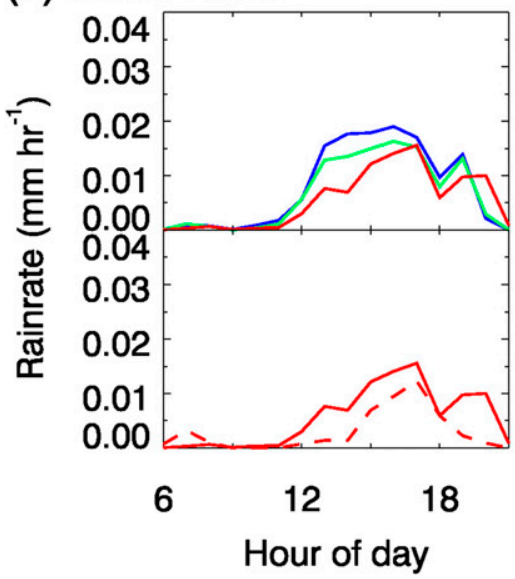

DCC

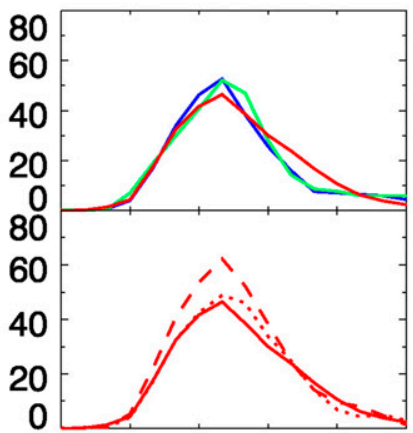

0

6

12
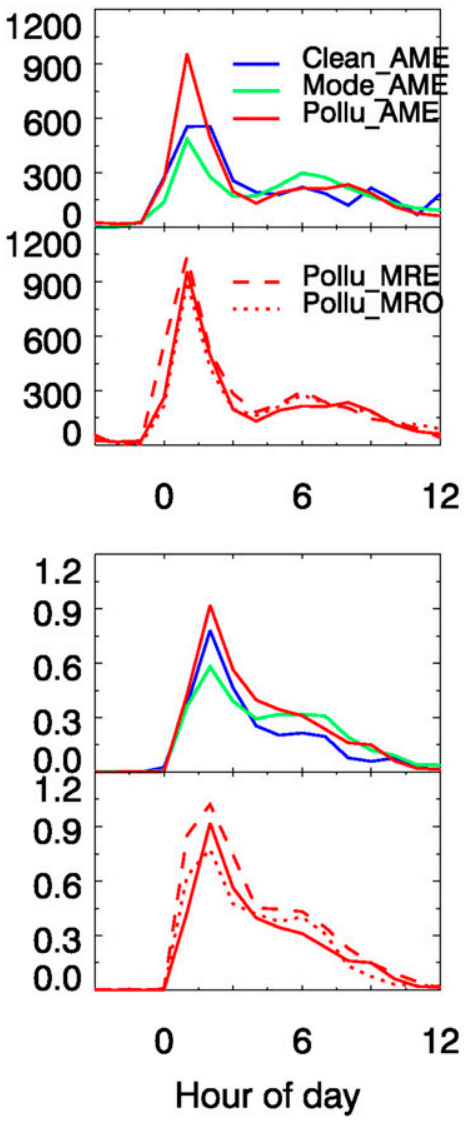

stratus

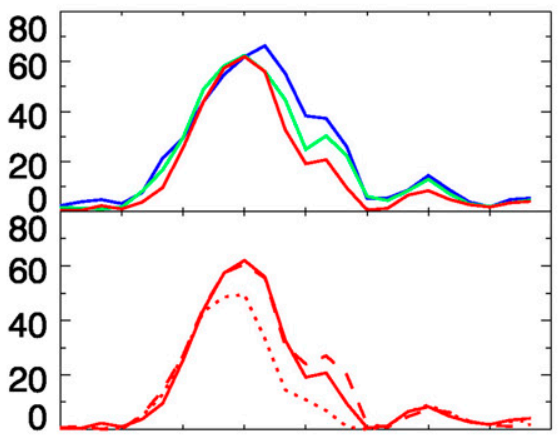

$\begin{array}{lll}0 & 6 & 12\end{array}$

18
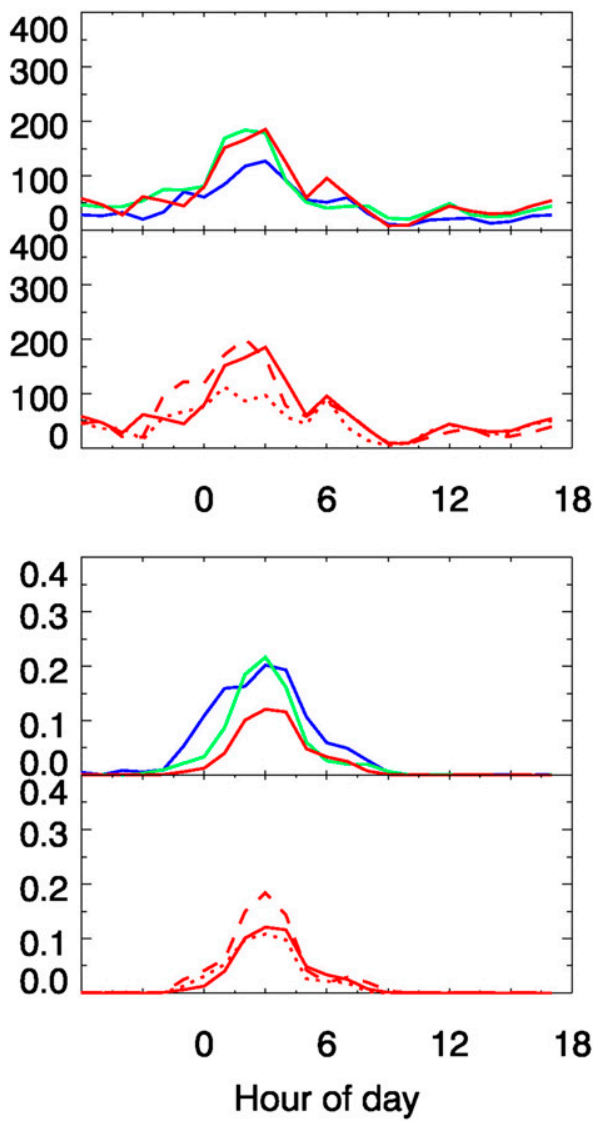

FIG. 5. Temporal evolutions of (a) the cloud fraction, (b) LWP, and (c) precipitation rate for the three cloud regimes under different aerosol conditions. Columns are for (left) shallow cumuli, (center) DCC, and (right) stratus. For each parameter, shown are (top) results under different aerosol scenarios without ARE, including Clean_AME (blue), Mode_AME (green), and Pollu_AME (red) cases, and (bottom) simulations with and without ARE for polluted conditions, including the case with AME only (Pollu_AME, solid line), the case with ARE and cloud-environment feedbacks (Pollu_MRE, dashed line), and the case with ARE but without cloud-environment feedbacks (Pollu_MRO, dotted line).

enhanced cloudiness of the DCC (Figs. 5a and 6a). For instance, the cloud fractions for the shallow cumuli and stratus are reduced by $40 \%$ and $27 \%$, respectively, from the Clean_AME to Pollu_AME runs. In MRE runs, the cloud fraction decreases with aerosols with a larger slope for the shallow cumuli and a smaller slope for the stratus. For the DCC, the cloudiness shows a nonmonotonic trend; that is, the cloud fraction decreases from the Clean to Mode runs but increases from the Mode to Pollu runs. For a given aerosol concentration, the DCC 
(a) CF Shallow cumulli

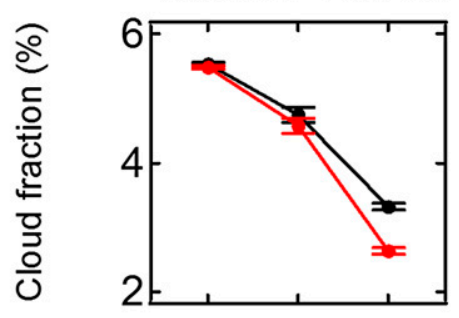

(b) LWP

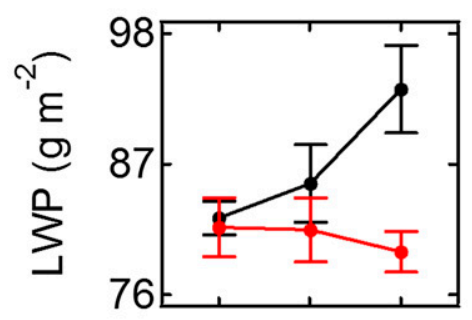

(c) Rain rate

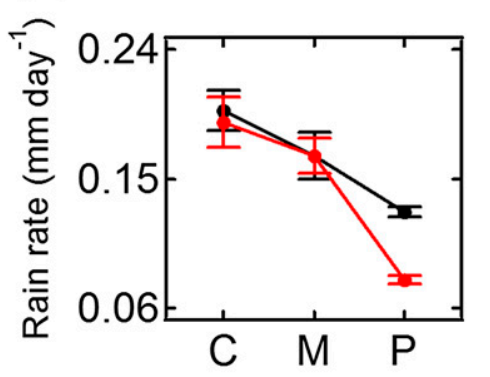

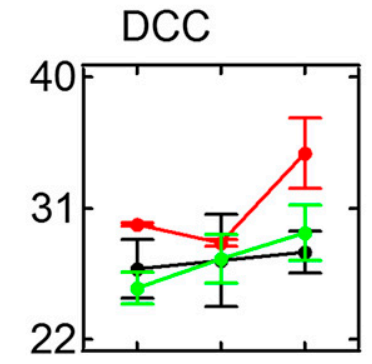
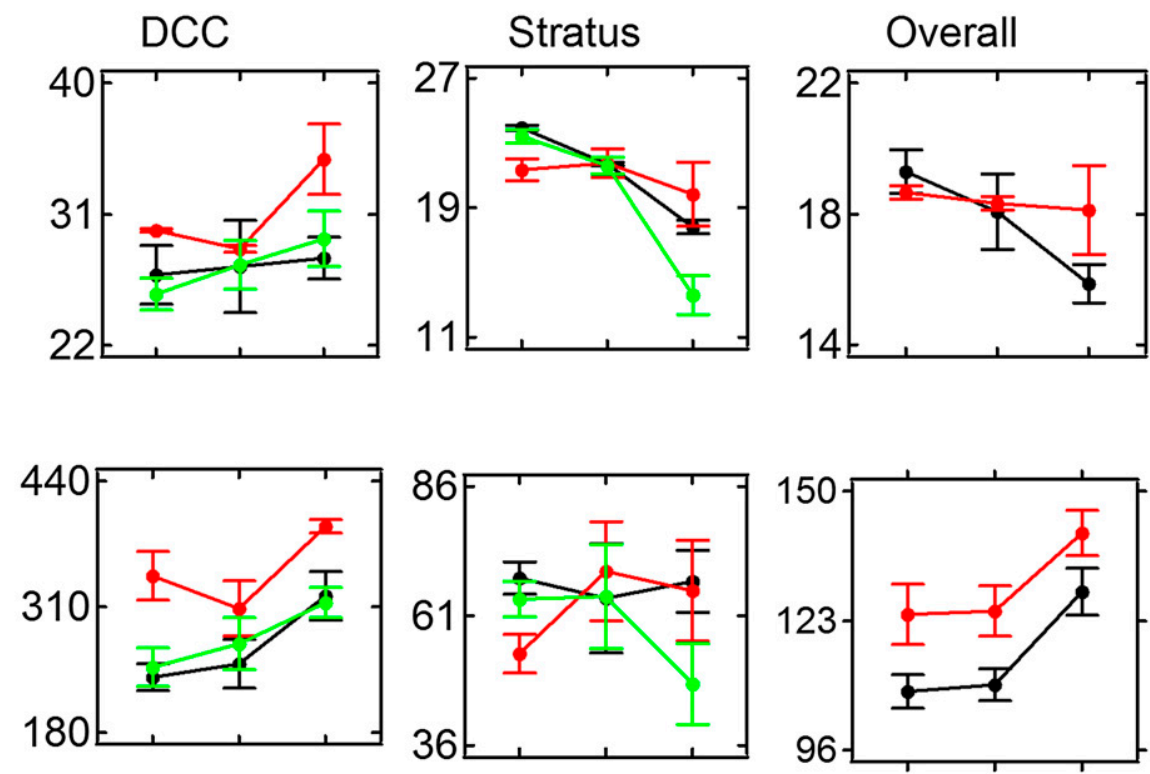

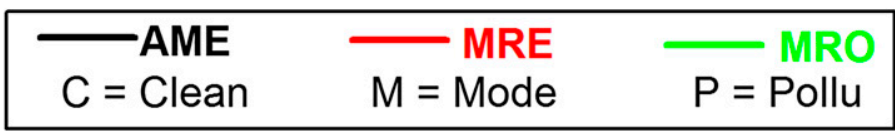

FIG. 6. (a) Domain-averaged cloud fraction, (b) cloud column mean of LWP, and (c) accumulated precipitation under the Clean, Mode, and Pollu aerosol scenarios for the (left)-(right) shallow cumuli, DCC, stratus, and overall effects. The black, red, and green lines are for the AME, MRE, and MRO runs, respectively. The vertical lines denote the error bars (one standard deviation), which are estimated from three ensembles conducted with small perturbations in the initial temperature condition.

cloud fraction is enhanced by $13 \%$ on average in MRE simulations relative to AME simulations. Also shown in Figs. $5 b$ and $6 b$, LWP for the shallow cumuli and DCC exhibits an increasing trend with increased aerosol in AME simulations. For example, from the Clean to Pollu runs, LWP increases by $13 \%$ and $35 \%$ for the shallow cumuli and DCC, respectively. LWP for the stratus appears to be insensitive to aerosol loadings. With ARE, the LWP trends are altered for all the three cloud regimes. For example, there is little change for LWP in MRE runs during the shallow cumuli period as aerosol increases. For the DCC and stratus, the LWP responses are nonmonotonic. Similar to the cloud fraction, LWP for the DCC in MRE runs is enhanced by $22 \% \sim 44 \%$ relative to AME runs. The responses of the domain-averaged precipitation rate to aerosol loading also depend on the cloud regimes (Figs. $5 \mathrm{c}$ and $6 \mathrm{c}$ ). The precipitation is significantly suppressed in the polluted shallow cumuli with or without ARE. There are monotonic responses in AME runs for the DCC and stratus clouds but nonmonotonic trends in MRE runs. At a given aerosol level, the precipitation rate associated with the DCC in MRE runs is considerably enhanced (on average by $30 \%$ ) compared to AME runs.

The suppressed surface precipitation $(-36 \%)$ from the Clean to Pollu runs leads to more liquid water, corresponding to a moderately enhanced LWP (13\%). However, the decrease in precipitation and the increase in LWP do not result in an enhancement of cloudiness but lead to a marked reduction in cloud fraction 
$(-40 \%)$. For the stratus, the precipitation rate is reduced by $55 \%$, while the cloud fraction decreases by $26 \%$. These responses are contrary to the expected second aerosol microphysics effect-that is, aerosolinduced precipitation suppression causing enhanced fractional cloudiness (Albrecht 1989). Several previous studies (e.g., Xue and Feingold 2006; Xue et al. 2008; Saleeby et al. 2010, 2015) have suggested that the aerosol effects on droplet evaporation compete with the effects on precipitation to control warm clouds. The condensation/evaporation rate in our microphysics scheme is dependent on droplet population and its mean size ( $\mathrm{Li}$ et al. 2008b). When the cloud droplet number concentration increases with aerosols (Fig. 4), there is a considerable decrease of the cloud droplet size for the shallow cumuli and stratus, suggesting more efficient evaporation of cloud droplets and less efficient conversion to raindrops under polluted conditions. The less cloudiness under the polluted condition for the shallow cumuli and stratus indicates that the effect of aerosolinduced enhancement of droplet evaporation dominates over the effect of aerosol-induced suppression of precipitation.

In contrast to the shallow cumuli and stratus, a monotonic increase of the surface precipitation (34\%) is evident from the Clean to Pollu runs when the DCC occurs. Note that the mean radius of raindrops in the DCC considerably increases when increasing aerosols (Fig. 4). Larger raindrops generated under the polluted condition have a higher probability of surviving evaporation when falling to ground level, producing more surface precipitation (Lim and Hong 2010). Since there is a notable increase in LWP (34\%) for the polluted DCC, the reduction in the liquid water due to more precipitation appears to be compensated by the enhanced liquid water by more efficient condensation growth, as evident by the elevated cloud water mass under the polluted condition (Fig. 4). More liquid water is responsible for a higher cloudiness. The cloud fraction of the DCC is enhanced by $7 \%$ from the Clean to Pollu runs (in Fig. 6). Since the amount of ice particles is insensitive to aerosols (Fig. 4), the invigoration of the DCC in terms of the enhanced LWP and precipitation (Figs. 5b, 5c, 6b, and 6c) is mainly explained by the efficient condensation of cloud water. The tendency of cloudiness to increase with aerosols for the DCC is in contrast to that for the shallow cumuli, perhaps because the DCC has a larger cloud size (a larger cloud fraction of $25 \%$ ) than the shallow cumuli (a smaller cloud fraction of $6 \%$ ), resulting in limited entrainment drying with a larger surface-to-volume ratio (Xue and Feingold 2006). Also, cloud droplets in the DCC are on average larger than those of the shallow cumuli by four microns at a given aerosol level, leading to less evaporation and more collision-coalescence growth of droplets in the DCC.

For the comparison between MRE and AME runs (Figs. 5 and 6), the cloudiness, LWP, and precipitation for the shallow cumuli are reduced with ARE. These reductions appear to be unrelated to the solar evaporation by soot-contained aerosols as implied in McFarquhar et al. (2004), because the mean droplet size is larger in the MRE than AME runs (Fig. 4). In fact, the weakened cloud microphysical response to aerosols with ARE (i.e., the weakened increasing trend of the cloud droplet number concentration in the MRE runs compared to the AME runs; Fig. 4) are likely responsible for these reductions because of the thermodynamics and dynamics effects by absorbing aerosols (also see discussion in section 3d). For the DCC and stratus clouds, the variations of the cloud fraction, LWP, and precipitation with aerosols are markedly modified by ARE, since those responses are monotonic in the AME runs but nonmonotonic in the MRE runs.

Also shown in Figs. 5 and 6, the simulations without the preceding cloud-environment feedbacks (MRO) is compared to the MRE and AME runs to estimate the contribution to the latter cloud changes from ARE on the DCC and stratus clouds. The comparison of MRE and MRO to AME indicates that ARE is overestimated using the contrast between MRE and AME. For example, the cloud fraction of DCC is enhanced by $14 \%$ from Pollu_AME to Pollu_MRO, but the cloud fraction is enhanced by $24 \%$ from Pollu_AME to Pollu_MRE. An examination of MRO shows that the micro- and macrophysics of DCC in the MRO run is closer to AME than to MRE. For the stratus, without the interference of development of the preceding clouds (Pollu_MRO), the polluted stratus cloud is suppressed by ARE (Fig. 5), similar to that of the shallow cumulus, and the macrophysiccal responses of stratus to aerosols behave monotonically, similar to the simulations with AME only (Fig. 6). For MRE, the macrophysical responses of the stratus are nonmonotonic because the impacts of the preceding cloud-environment interactions are included. The nonlinear ARE on the environment through their impacts on the preceding clouds is larger than those for the DCC and stratus clouds. Since this study focuses on the aerosol effects on a continuously evolving system, the ARE impacts on the preceding cloud-environment interactions are included when assessing the aerosol radiative effects on the DCC and stratus clouds.

\section{$d$. Latent heating and convection strength}

The latent heating rates and updraft mass flux are examined to reveal the aerosol-thermodynamic and dynamic feedbacks. The vertical profiles of latent 
Shallow cumuli

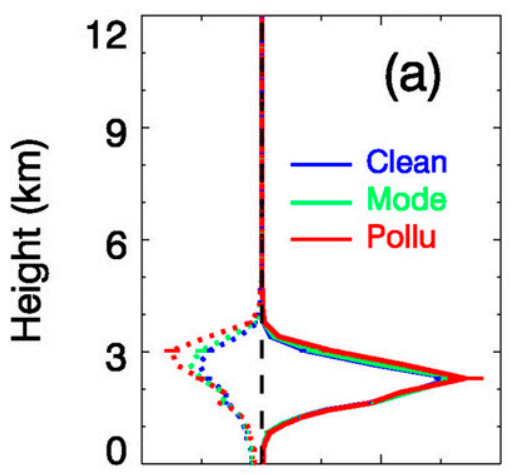

$\begin{array}{llll}-4 & 0 & 4 & 8\end{array}$

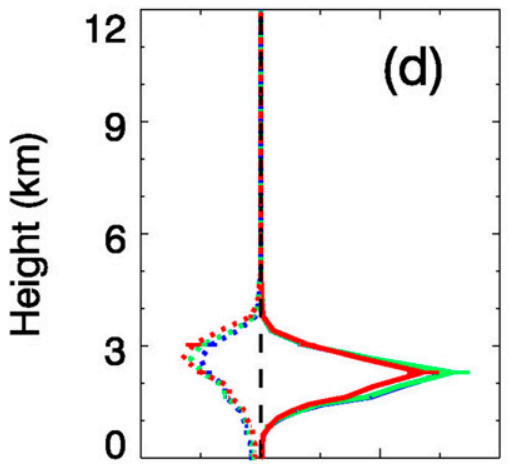

$\begin{array}{llll}-4 & 0 & 4 & 8\end{array}$

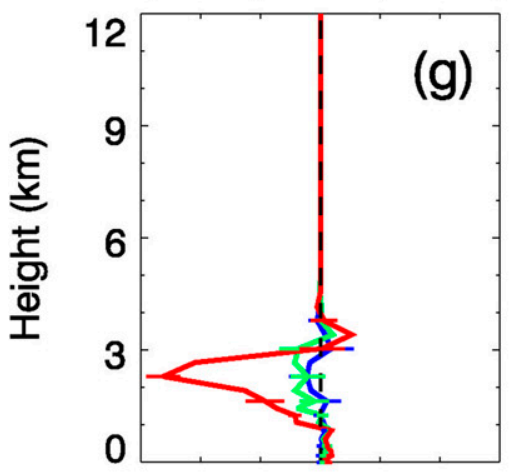

$\begin{array}{lll}-1.5 & 0.0 & 1.5\end{array}$

Latent heating rate $\left(\mathrm{K} \mathrm{hr}^{-1}\right)$
DCC
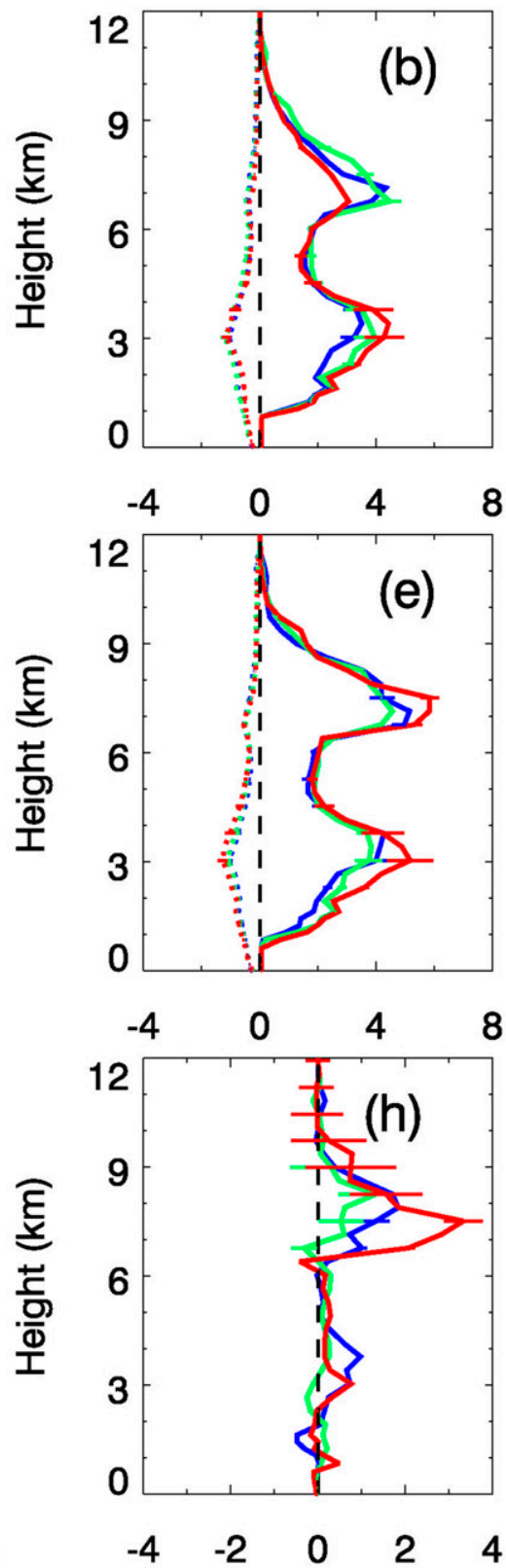

Latent heating rate $\left(\mathrm{K} \mathrm{hr}^{-1}\right)$
Stratus
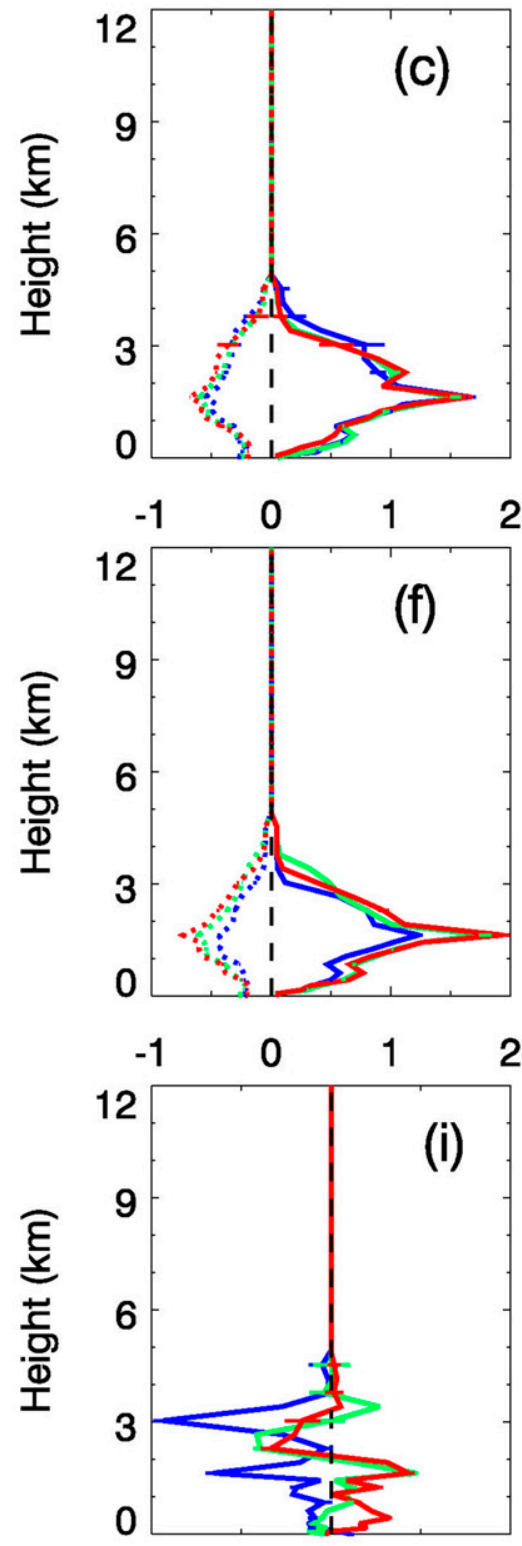

$\begin{array}{lll}-0.5 & 0.0 & 0.5\end{array}$

Latent heating rate $\left(\mathrm{K} \mathrm{hr}^{-1}\right)$

FIG. 7. Vertical profiles of the latent heating rates for the three cloud regimes under the different aerosol scenarios. Columns correspond to the (left) shallow cumuli, (center) DCC, and (right) stratus. (a)-(c) The AME runs and (d)-(f) the MRE runs. The solid and dotted lines in (a)-(f) represent the heating and cooling rates, respectively. (g)-(i) The difference in the net latent heating rates between the MRE and AME runs. The net heating rates are equal to the sum of the heating and cooling rates. The blue, green, and red lines denote the Clean, Mode, and Pollu runs, respectively. The horizontal lines denote the error bars (one standard deviation), which are estimated from the three ensembles conducted with small perturbations in the initial temperature condition.

heating rates as well as the changes in net heating rate between the MRE and AME runs are shown in Fig. 7. The net heating rate is decomposed into the heating due to condensation (or freezing and riming for DCC) and the cooling due to evaporation (or sublimation and melting for DCC). All rates are averaged over the domain and the corresponding cloud periods. The mean updraft mass flux shown in Fig. 8 is determined as the 
Shallow cumuli
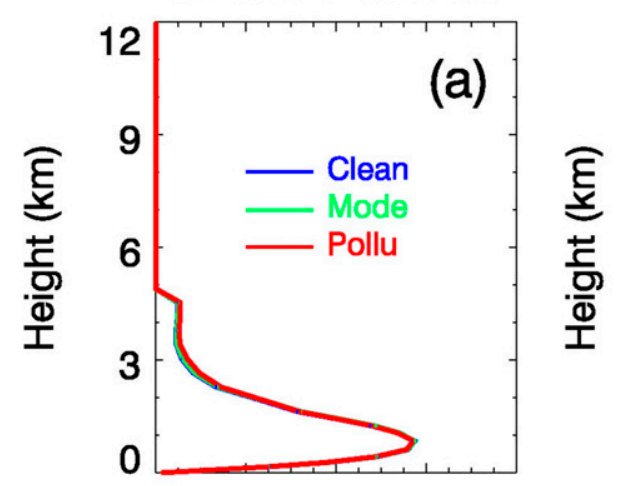

$\begin{array}{lllll}0.0 & 0.2 & 0.4 & 0.6 & 0.8\end{array}$
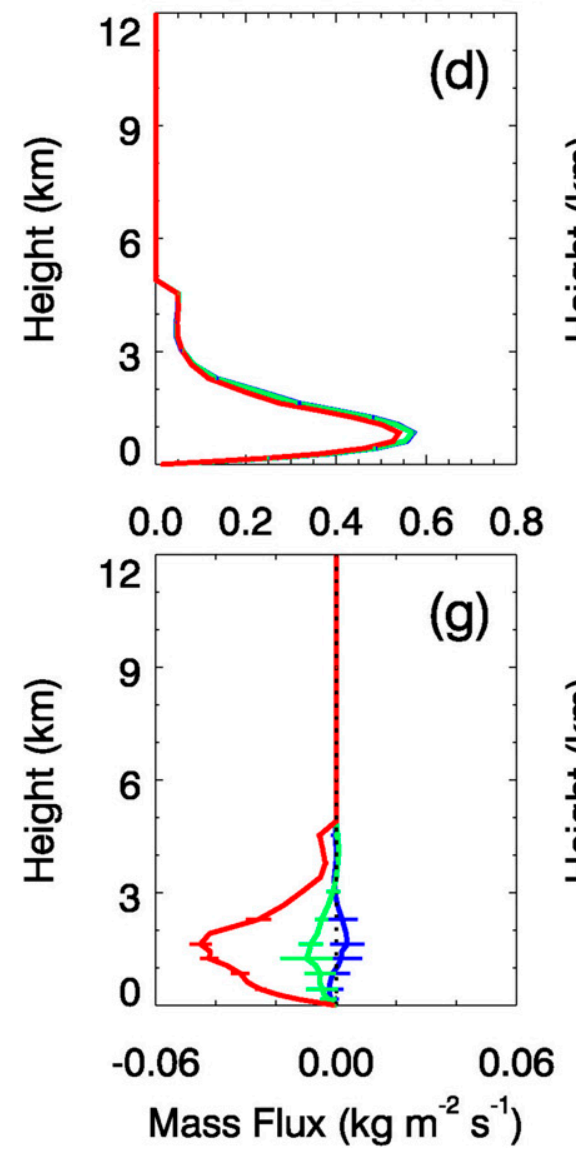

DCC
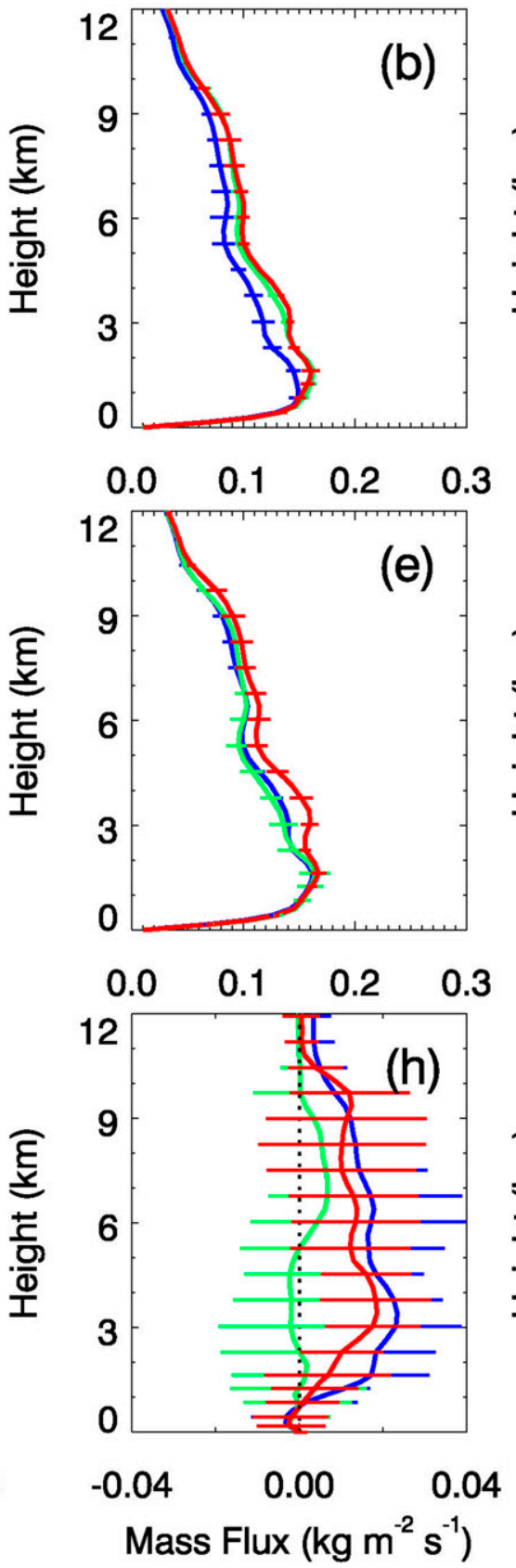

Stratus
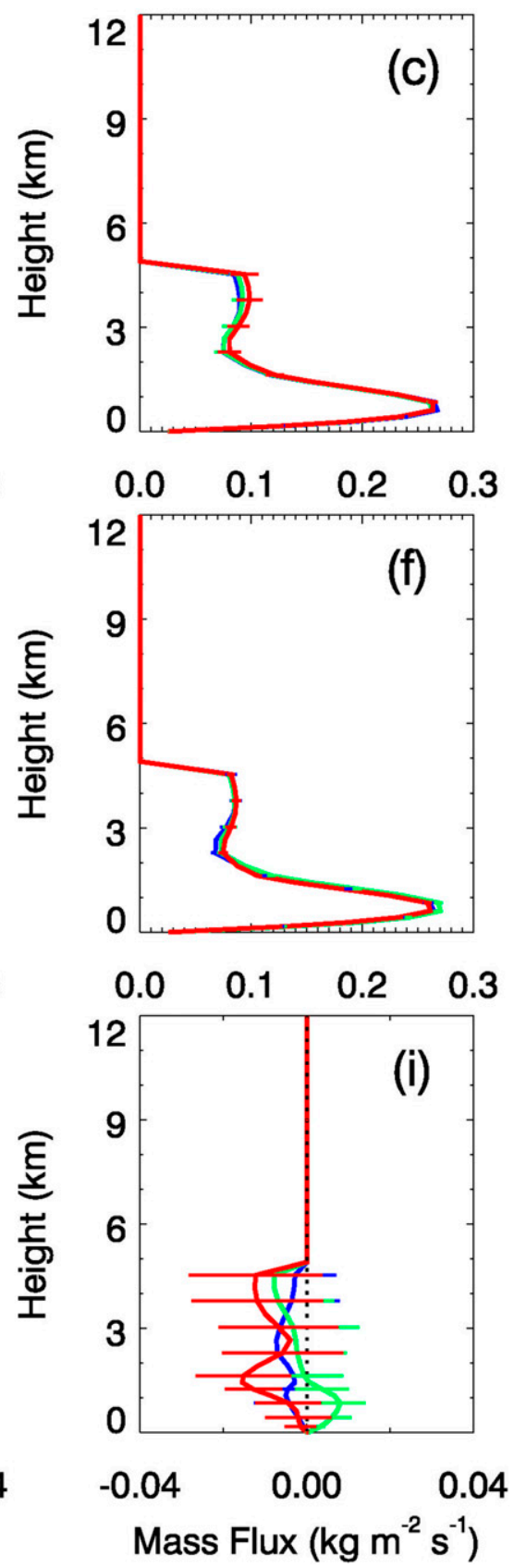

FIG. 8. Vertical profiles of the updraft mass flux (vertical velocity $>0 \mathrm{~m} \mathrm{~s}^{-1}$ ) for the three cloud regimes under the different aerosol scenarios. Columns correspond to the (left) shallow cumuli, (center) DCC, and (right) stratus. (a)-(c) The AME runs, (d)-(f) the MRE runs, and (g)-(i) the differences in the mass flux between the MRE and AME runs. The blue, green, and red lines denote the Clean, Mode, and Pollu runs, respectively. The horizontal lines denote the error bars (one standard deviation), which are estimated from three ensembles conducted with small perturbations in the initial temperature condition.

product of the vertical velocity and air density for all grids with a nonzero vertical velocity (Morrison 2012). The difference of the updraft mass flux between the MRE and AME runs is also presented. The horizontal lines in Figs. 7 and 8 represent the error bars calculated for one standard deviation. A $t$ test performed at a significance level of $5 \%$ indicates that the AME on updraft mass flux for the DCC is statistically significant, and the ARE on the latent heating and updraft mass flux is statistically significant for the shallow cumuli and DCC. 
For the AME runs in Figs. 7a and 7c, the heating due to condensation is insensitive to aerosols during the shallow cumuli and the stratus periods, but the cooling due to evaporation is intensified with increasing aerosols. The stronger cooling at a higher aerosol level indicates that the more efficient evaporation due to the larger amount of smaller droplets under the polluted condition leads to reductions in cloudiness of the shallow cumulus and stratus clouds. The enhanced cooling likely causes a stronger downward motion (Xue and Feingold 2006), further suppressing the two cloud regimes. However, the corresponding updraft mass fluxes are insensitive to aerosols (Figs. 8a and 8c), perhaps because of litter changes in the latent heat released. The response of the heating during the DCC period depends on the altitude (Fig. 7b); that is, the heating increases monotonically at low altitudes (below $4 \mathrm{~km}$ ) but nonmonotonically at high altitudes (above $6 \mathrm{~km}$ ). The increase in heating at low altitudes suggests more efficient condensation in the polluted DCC, as reflected by the higher cloud water mass of the DCC in the Pollu run (Fig. 4). As a result, the convection for the polluted DCC is invigorated (Fig. 8b), leading to the increases in cloudiness, LWP, and precipitation (Fig. 5 and 6). Above $6 \mathrm{~km}$, the increasing trend in mass flux is inconsistent with the decreasing trend in latent heating, probably owing to the continuous influence of the invigoration of updrafts in the lower atmosphere (below $4 \mathrm{~km}$ ). Also note that the cold pools exist just below the DCC (the peaks of the cooling rates in Fig. 7b), corresponding to the evaporative cooling induced by precipitation. Those cold pools are important for cloud maintenance (Tao et al. 2007; Grant and van den Heever 2015). For the DCC case, the cold pools are insensitive to aerosols, suggesting that the aerosol-cold pool interaction is not a key factor controlling the DCC characteristics in this study.

With ARE, the tendency of the cooling to increasing aerosols for the shallow cumuli is weakened, indicating less efficient evaporative cooling in the MRE runs. The microphysical features (Fig. 4) also show that, at a same aerosol level, droplets in the MRE runs are on average larger than those of the AME runs, leading to a reduced surface-to-volume ratio of droplets in the MRE runs and suppressed evaporation. The heating in the MRE runs exhibits a weak decreasing trend (Fig. 7d). Correspondingly, the updraft mass flux decreases with aerosols (Fig. 8d). By contrasting the ARE and AME runs, the differences in the net heating rate as well as the updraft mass flux tend to be more negative under the polluted condition (Figs. $7 \mathrm{~g}$ and $8 \mathrm{~g}$ ), suggesting that the reduced latent heat and suppressed updraft by ARE are more significant at a higher aerosol level. The suppressed updraft results in the reduced cloud fraction, smaller LWP, and less precipitation for the shallow cumuli (Fig. 6).

The convection of DCC in the MRE runs shows a nonmonotonic response to aerosols (Fig. 8e), corresponding to the nonmonotonic trend of the latent heating (Fig. 7e). The nonmonotonic responses of the latent heating and convection lead to the nonmonotonic responses of cloudiness, LWP, and precipitation shown in Fig. 6. In Figs. $7 \mathrm{~h}$ and $8 \mathrm{~h}$, the differences in the net latent heating rate and updraft mass flux between MRE and AME runs are positive, representing a stronger convection in the MRE than AME runs. These positive changes explain the invigorated DCC-that is, the enhanced cloudiness, LWP, and precipitation shown in Fig. 6. For the stratus, the aerosol-induced increase in the cooling rate competes with the increase in the heating rate, and both control the updraft responses to aerosols shown in Figs. $8 \mathrm{c}$ and $8 \mathrm{f}$. As a result, the differences in the net latent heating rate and updraft mass flux between the MRE and AME runs are either positive or negative for the different aerosol levels (Figs. 7i and 8i), resulting in the complexity of the aerosol-stratus cloud interactions with ARE as shown in Figs. 4 and 6.

\section{e. Thermodynamic and dynamic effects by ARE}

The modifications of the thermodynamic and dynamic conditions by ARE are examined by contrasting the polluted MRE and AME runs in terms of the temporal evolution of the various environmental parameters, including the radiative heating rate, temperature, relative humidity, cloud water content, equivalent potential temperature, updrafts, and downdrafts as shown in Fig. 9.

As shown in Fig. 9a, the positive changes in the heating rate by shortwave radiation are observed repeatedly from 0600 to1800 LST each day, representing a significant absorption of solar radiation by sootcontained aerosols in the MRE runs. The peak value of the heating rates for the Pollu case with ARE is $2.9 \mathrm{~K} \mathrm{day}^{-1}, 0.7 \mathrm{~K} \mathrm{day}^{-1}$ higher than that of the Pollu case without ARE. During the shallow cumuli period (i.e., daytime on 25 May), the solar absorption causes warming in the low troposphere, as reflected by the positive changes in temperature around $1-3 \mathrm{~km}$ in Fig. 9b, and cooling at the surface, as reflected by the negative changes in temperature near the surface in Fig. 9b. As a consequence, the atmosphere is stabilized, evident by the negative changes in the equivalent potential temperature in Fig. 9e. The more unstable atmosphere explains the weaker updrafts and downdrafts during the shallow cumuli period in Figs. 9f and $9 \mathrm{~g}$ as well as the smaller updraft mass flux for the polluted condition in Fig. 8g. The relative humidity is 


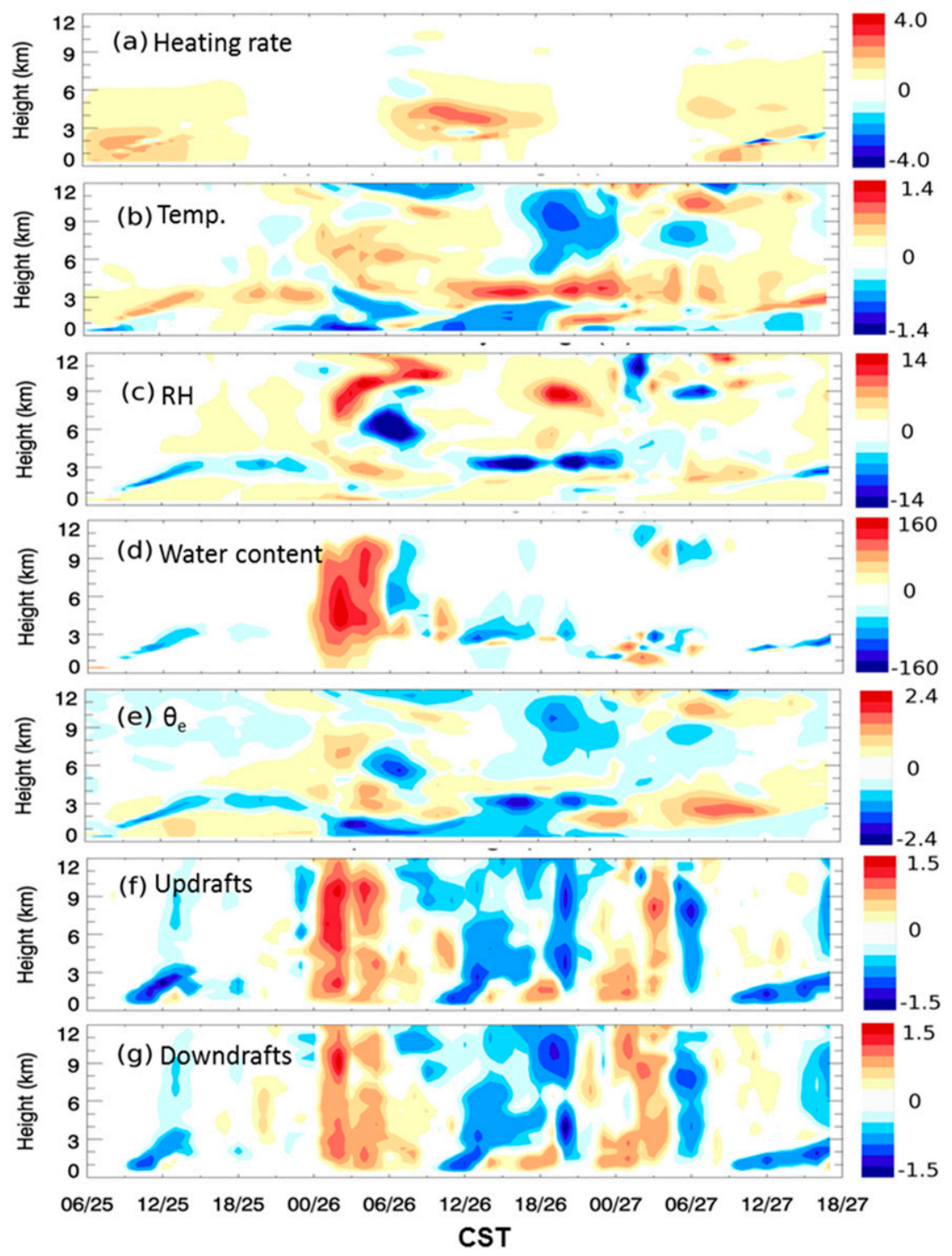

FIG. 9. Temporal evolution of the differences in (a) the heating rate by shortwave radiation $\left(\mathrm{K}_{\text {day }}{ }^{-1}\right)$; (b) temperature (Temp; K); (c) relative humidity (RH; \%); (d) cloud water content $\left(\mathrm{mg} \mathrm{kg}^{-1}\right)$; (e) equivalent potential temperature $\theta_{e}(\mathrm{~K})$; (f) updrafts $\left(\mathrm{m} \mathrm{s}^{-1}\right)$; and $(\mathrm{g})$ downdrafts $\left(\mathrm{m} \mathrm{s}^{-1}\right)$ between the Pollu_MRE and Pollu_AME runs (i.e., MRE - AME).

considerably reduced (Fig. 9c) because less moisture is transported to the cloud region owing to the weakened updraft. As a result, the shallow cumuli are suppressed by ARE, as reflected by a lower cloudiness and smaller LWP (Fig. 6) as well as the negative changes in the cloud water content (Fig. 9d).

The positive changes in the cloud water content during the DCC period (Fig. 9d) are associated with the enhanced atmospheric instability, since the convective available potential energy (CAPE) prior to the DCC formation (at 2300 LST 25 May) is $60 \mathrm{~J} \mathrm{~kg}^{-1}$ higher in the
Pollu_AME than Pollu_MRE runs. Consistently, the positive changes in the equivalent potential temperature are shown just before the DCC formation (Fig. 9e), suggesting a more unstable atmosphere with ARE. The increased instability as well as the invigorated convection (Figs. 9f and 9g) in the early morning on 26 May is possibly triggered by the heating effect of absorbing aerosols during the daytime of 25 May. Also note that the positive changes in relative humidity during the DCC period suggest more water vapor transported to the upper troposphere because of the stronger updrafts (Figs. 9f and 8h). 
As a result, the cloud microphysical processes in DCC, such as graupel formation and growth, are strengthened by ARE (i.e., from the enhanced graupel mass, number, and size from the AME to MRE runs in Fig. 4), leading to the higher LWP and more precipitation (Fig. 6). The underlying mechanism for the invigorated DCC in our study is similar to the "aerosol-enhanced conditional instability" mechanism, which has been demonstrated by Grant and van den Heever (2014) and Fan et al. (2015). For example, Fan et al. (2015) has documented that the daytime convection is suppressed with increased atmospheric stability by light-absorbing aerosols, resulting in an excess moist air mass transported downwind at night and causing stronger convection at the downwind area as well as more heavy precipitation. The difference between this study and Fan et al. (2015) is that the aerosol-enhanced conditional instability occurs at the downwind area in Fan et al. (2015) but at the source region in this study.

The interactions between aerosols and the stratus are complicated because of the ARE impacts on the environment feedbacks of the shallow cumuli and DCC. Under the polluted condition, the increased cloud water content of the nighttime stratus (from 0000 to 0600 LST 27 May) is explained by the enhanced instability and invigorated convection (Figs. 9e-g). The daytime stratus (from 0900 to 1800 LST 27 May) tends to be suppressed by aerosol heating, as reflected by the negative changes in the cloud water content and vertical velocities (Figs. 9d, 9f, and 9g).

\section{$f$. The overall effects of aerosols on the cloud complex}

The overall aerosol effects on the evolving cloud complex are shown in Fig. 6 in terms of the domainaveraged cloud fraction, LWP, and rainfall rate averaged over the entire cloud period. It is evident that the aerosol net effects on the cloud complex are noticeably different from the aerosol effects on the individual cloud regimes. For instance, the mean cloud fraction over all the three cloud regimes slightly decreases from $19 \%$ (19\%) to $16 \%$ (18\%) from the Clean to Pollu runs with AME (MRE). The overall LWP and rainfall rate increase with aerosols for the AME and MRE runs. These trends of the evolving cloud complex are distinct from those of its individual cloud regime, suggesting that the aerosol effects associated with an individual cloud regime likely offset or compensate with each other via a buffering effect (van den Heever et al. 2011). The overall aerosol effects for the 3-day simulation are statistically significant (i.e., the relatively small error bars in Fig. 6), in contrast to the weak effects by van den Heever et al. (2011) with a much longer simulation (40 days) performed. Since the overall response of the cloud properties to aerosols for the evolving cloud complex is distinct from those of its individual cloud components, it is necessary to evaluate the long-term response of the various cloud types when assessing the aerosol direct and indirect radiative forcings.

\section{Summary and conclusions}

The aerosol microphysical and radiative effects on an evolving continental cloud complex occurring from 25 May to 27 May 2009 during the DOE ARM RACORO field campaign are investigated. The TAMUWRF model with a two-moment bulk microphysics by $\mathrm{Li}$ et al. (2008b) and a modified Goddard radiation scheme by Fan et al. (2008) is employed to investigate the AME and ARE. The activation of aerosols to $\mathrm{CCN}$ is estimated by assuming a chemical composition of either pure ammonium sulfate or ammonium sulfate containing a small fraction $(5 \%)$ of black carbon when evaluating the aerosol radiative effect. Two typical boundary layer clouds (shallow cumuli and 1-day persisting stratus) and a DCC associated with a prefrontal convective line are simulated in this cloud complex. Comparison of the cloud fraction between simulations and measurements shows that the temporal evolutions of cloud fractions of the different clouds and the transition of the cloud types at the SGP central facility are reproduced in the simulations, but the modeled stratus is discontinuous and the cloud fractions of the shallow cumuli and the stratus are underestimated. The simulated LWP and precipitation generally agree temporally with the observations, but the simulations underestimate the magnitude of LWP for the stratus and peak value of precipitation for the DCC.

The simulated mass and number concentrations and effective radii of cloud droplets and raindrops for all the three cloud regimes exhibit overall monotonic responses to initial aerosol concentrations with or without ARE. A higher aerosol level yields more numerous $\mathrm{CCNs}$ for water vapor to condensate but inhibits the conversion of cloud droplets to raindrops, explaining the enhancement of cloud droplet nucleation and the suppression of raindrop formation. The overall change in ice water content induced by aerosols is insignificant, but the onset of ice formation was delayed in AME. The comparison of AME and MRE simulations implies that at a given aerosol level shallow cumuli are suppressed while the DCC is invigorated with ARE. The microphysical response of raindrops for the stratus behaves differently with ARE, suggesting that ARE has significant impacts on the stratus rainwater. Note that the ARE discussed in this study for the DCC and stratus clouds also contains the impacts of the environmental feedbacks through ARE influences on the preceding cloud regimes. 
The responses of the cloud fraction, LWP, and precipitation to aerosols depend on the cloud regimes. The cloud fraction for shallow cumuli and the stratus decreases with aerosols due to AME, indicating that the aerosol-induced suppression of precipitation is dominated by aerosol-induced intensification of droplet evaporation, as suggested by Xue et al. (2008). For the DCC, the increases in cloudiness, LWP, and precipitation with increasing aerosols are due to more efficient condensation and less efficient evaporation, corresponding to enhanced latent heating at low altitude and updraft mass flux. ARE tends to reduce cloudiness and precipitation associated with shallow cumuli, likely because of a weakened cloud microphysical response to the changes in aerosol concentration with ARE. ARE exhibits a remarkable influence on the trends of cloud fraction, LWP, and precipitation for the DCC and stratus clouds, since their responses to aerosol are monotonic with AME only but nonmonotonic with both AME and ARE. Because there are less cloudiness and smaller LWP for the two simulated boundary layer clouds under the polluted condition, the loss dominates over generation for the condensate mass. In comparison, Khain et al. (2008) have found that both the generation and the loss of the condensate mass can be enhanced in the polluted condition for warm-cloud-base clouds.

Simulations with and without ARE under the polluted condition show distinct characteristics of the cloud micro- and macrophysics, because of the changes in atmospheric instability and thermodynamics caused by ARE. Because of the radiative heating from soot particles, the convection strength and relative humidity are both reduced during daytime. Subsequently, cloud amounts of the shallow cumuli are decreased in ARE. The increasing atmospheric instability by absorbing aerosols alters the temperature and moisture conditions during daytime and further leads to an enhanced atmospheric instability and excess moisture at night and a favorable condition for the nighttime DCC formation, similar to the "aerosol-enhanced conditional instability" mechanism previously demonstrated by Grant and van den Heever (2014) and Fan et al. (2015).

The buffering effect of one cloud regime on another makes the overall aerosol effects of the cloud complex distinctly different from any of the individual cloud types, consistent with van den Heever et al. (2011). Hence, the aerosol-cloud interaction for the diverse cloud regimes and their transitions throughout the cloud life cycle needs to be evaluated to assess the overall aerosol direct and indirect radiative forcings on regional and global climate. Future statistical study on long-term observations and/or modeling simulations is also necessary to more accurately examine the comprehensive aerosol effects on clouds and precipitation. Also, case studies associated with various synoptic setups need to be selected to improve the representation of aerosol-cloud interactions and test the robustness of conclusions drawn from this work.

Acknowledgments. This research is supported by DOE's Earth System Modeling (ESM) Program via the FASTER project (www.bnl.gov/faster), under Grant DOE-DE-AC02-98CH10886. The RACORO field campaign was supported by DOE's ARM program. We are grateful for discussions on RACORO with Dr. Andrew Vogelmann at BNL and on aerosol microphysics effects on various clouds with Dr. Jonathan H. Jiang at JPL. The data from the RACORO field campaign, utilized only for education and research, are open to public after registration and application. Supercomputing computational facilities were provided by the Texas A\&M University. Yuan Wang's contribution to this work was sponsored by NASA ROSES14-ACMAP and was carried at the Jet Propulsion Laboratory, California Institute of Technology, under a contract with NASA (Grant 105357281945.02.31.03.24).

\section{REFERENCES}

Abdul-Razzak, H., S. J. Ghan, and C. Rivera-Carpio, 1998: A parameterization of aerosol activation: 1. Single aerosol type. J. Geophys. Res., 103, 6123-6131, doi:10.1029/97JD03735.

Ackerman, A. S., O. B. Toon, D. E. Stevens, A. J. Heymsfield, V. Ramanathan, and E. J. Welton, 2000: Reduction of tropical cloudiness by soot. Science, 288, 1042-1047, doi:10.1126/ science.288.5468.1042.

Albrecht, B. A., 1989: Aerosols, cloud microphysics, and fractional cloudiness. Science, 245, 1227-1230, doi:10.1126/ science.245.4923.1227.

Allen, R. J., and S. C. Sherwood, 2010: Aerosol-cloud semi-direct effect and land-sea temperature contrast in a GCM. Geophys. Res. Lett., 37, L07702, doi:10.1029/2010GL042759.

Andreae, M. O., D. Rosenfeld, P. Artaxo, A. A. Costa, G. P. Frank, K. M. Longo, and M. A. F. Silva-Dias, 2004: Smoking rain clouds over the Amazon. Science, 303, 1337-1342, doi:10.1126/ science.1092779.

Bigg, E. K., 1953: The formation of atmospheric ice crystals by the freezing of droplets. Quart. J. Roy. Meteor. Soc., 79, 510-519, doi:10.1002/qj.49707934207.

Bond, D. W., S. Steiger, R. Y. Zhang, X. X. Tie, and R. E. Orville, 2002: The importance of $\mathrm{NO}_{X}$ production by lightning in the tropics. Atmos. Environ., 36, 1509-1519, doi:10.1016/ S1352-2310(01)00553-2.

Charlson, R. J., and M. J. Pilat, 1969: Climate: The influence of aerosols. J. Appl. Meteor., 8, 1001-1002, doi:10.1175/ 1520-0450(1969)008<1001:CTIOA > 2.0.CO;2.

Chou, M. D., and M. J. Suarez, 1999: A solar radiation parameterization for atmospheric studies. NASA Tech. Rep. Series on Global Modeling and Data Assimilation, Vol 15, NASA Tech. Memo. NASA/TM-1999-104606, 51 pp. [Available online at http://ntrs.nasa.gov/archive/nasa/casi.ntrs.nasa. gov/19990060930.pdf.] 
Coakley, J. A., R. D. Cess, and F. B. Yurevich, 1983: The effect of tropospheric aerosols on the Earth's radiation budget: A parameterization for climate models. J. Atmos. Sci. 40, 116-138, doi:10.1175/1520-0469(1983)040<0116:TEOTAO > 2.0.CO;2.

DeMott, P. J., and Coauthors, 2011: Resurgence in ice nuclei measurement research. Bull. Amer. Meteor. Soc., 92, 1623-1635, doi:10.1175/2011BAMS3119.1.

Fan, J., R. Y. Zhang, G. H. Li, J. Nielsen-Gammon, and Z. Q. Li, 2005: Simulations of fine particulate matter (PM2.5) in Houston, Texas. J. Geophys. Res., 110, D16203, doi:10.1029/ 2005JD005805.

,,--- , and W.-K. Tao, 2007a: Effects of aerosols and relative humidity on cumulus clouds. J. Geophys. Res., 112, D14204, doi:10.1029/2006JD008136.

,,,$----\longrightarrow$, and X. Li, 2007b: Simulations of cumulus clouds using a spectral microphysics cloud-resolving model. J. Geophys. Res., 112, D04201, doi:10.1029/2006JD007688.

,-- , W.-K. Tao, and K. I. Mohr, 2008: Effects of aerosol optical properties on deep convective clouds and radiative forcing. J. Geophys. Res., 113, D08209, doi:10.1029/2007JD009257.

— L. R. Leung, D. Rosenfeld, Q. Chen, Z. Li, J. Zhang, and H. Yan, 2013: Microphysical effects determine macrophysical response for aerosol impacts on deep convective clouds. Proc. Natl. Acad. Sci. USA, 110, E4581-E4590, doi:10.1073/ pnas. 1316830110.

— , D. Rosenfeld, Y. Yang, C. Zhao, L. R. Leung, and Z. Q. Li, 2015: Substantial contribution of anthropogenic air pollution to catastrophic floods in Southwest China. Geophys. Res. Lett., 42, 6066-6075, doi:10.1002/2015GL064479.

Ghan, S. J., L. R. Leung, R. C. Easter, and K. Abdul-Razzak, 1997: Prediction of cloud droplet number in a general circulation model. J. Geophys. Res., 102, 21 777-21 794, doi:10.1029/97JD01810.

Grant, L. D., and S. C. van den Heever, 2014: Aerosol-cloud-land surface interactions within tropical sea breeze convection. J. Geophys. Res., 119, 8340-8361, doi:10.1002/2014JD021912.

— aerosol loading: Modulation by dry layers. J. Atmos. Sci., 72, 1398-1408, doi:10.1175/JAS-D-14-0260.1.

Guo, S., and Coauthors, 2014: Elucidating severe urban haze formation in China. Proc. Natl. Acad. Sci. USA, 111, 1737317378, doi:10.1073/pnas.1419604111.

Hansen, J., M. Sato, and R. Ruedy, 1997: Radiative forcing and climate response. J. Geophys. Res., 102, 6831-6864, doi:10.1029/ 96JD03436.

Hong, S. Y., Y. Noh, and J. Dudhia, 2006: A new vertical diffusion package with an explicit treatment of entrainment processes. Mon. Wea. Rev., 134, 2318-2341, doi:10.1175/MWR3199.1.

IPCC, 2013: Climate Change 2013: The Physical Science Basis. Cambridge University Press, 1535 pp., doi:10.1017/ CBO9781107415324.

Jiang, H., and G. Feingold, 2006: Effect of aerosol on warm convective clouds: Aerosol-cloud-surface flux feedbacks in a new coupled large eddy model. J. Geophys. Res., 111, D01202, doi:10.1029/2005JD006138.

Jiang, J. H., and Coauthors, 2011: Influence of convection and aerosol pollution on ice cloud particle effective radius. Atmos. Chem. Phys., 11, 457-463, doi:10.5194/acp-11-457-2011.

Johnson, B. T., K. P. Shine, and P. M. Forster, 2004: The semidirect aerosol effect: Impact of absorbing aerosols on marine stratocumulus. Quart. J. Roy. Meteor. Soc., 130, 1407-1422, doi:10.1256/qj.03.61.

Kaufman, Y. J., I. Koren, L. A. Remer, D. Rosenfeld, and Y. Rudich, 2005: The effect of smoke, dust, and pollution aerosol on shallow cloud development over the Atlantic Ocean. Proc. Natl. Acad. Sci. USA, 102, 11207-11212, doi:10.1073/ pnas.0505191102.

Khain, A. P., 2009: Notes on state-of-the-art investigations of aerosol effects on precipitation: A critical review. Environ. Res. Lett., 4, 015004, doi:10.1088/1748-9326/4/1/015004.

- D. Rosenfeld, and A. Pokrovsky, 2005: Aerosol impact on the dynamics and microphysics of deep convective clouds. Quart. J. Roy. Meteor. Soc., 131, 2639-2663, doi:10.1256/qj.04.62.

_ N. BenMoshe, and A. Pokrovsky, 2008: Factors determining the impact of aerosols on surface precipitation from clouds: An attempt at classification. J. Atmos. Sci., 65, 1721-1748, doi:10.1175/2007JAS2515.1.

Kogan, Y. L., D. B. Mechem, and K. Choi, 2012: Effects of sea-salt aerosols on precipitation in simulations of shallow cumulus. J. Atmos. Sci., 69, 463-483, doi:10.1175/ JAS-D-11-031.1.

Lee, S. S., and G. Feingold, 2013: Aerosol effects on the cloud-field properties of tropical convective clouds. Atmos. Chem. Phys., 13, 6713-6726, doi:10.5194/acp-13-6713-2013.

_ L. J. Donner, and V. T. J. Phillips, 2009: Sensitivity of aerosol and cloud effects on radiation to cloud types: Comparison between deep convective clouds and warm stratiform clouds over one-day period. Atmos. Chem. Phys., 9, 2555-2575, doi:10.5194/acp-9-2555-2009.

$\longrightarrow,-\longrightarrow$, and J. E. Penner, 2010: Thunderstorm and stratocumulus: How does their contrasting morphology affect their interactions with aerosols? Atmos. Chem. Phys., 10, 68196837, doi:10.5194/acp-10-6819-2010.

Lei, W. F., A. Derecskei-Kovacs, and R. Y. Zhang, 2000: Ab initio study of $\mathrm{OH}$ addition reaction to isoprene. J. Chem. Phys., 113, 5354-5360, doi:10.1063/1.1290020.

Levy, M. E., and Coauthors, 2013: Measurements of submicron aerosols in Houston, Texas during the 2009 SHARP field campaign. J. Geophys. Res. Atmos., 118, 10518-10534, doi:10.1002/jgrd.50785.

Li, G., Y. Wang, K.-H. Lee, Y. Diao, and R. Zhang, 2008a: Increased winter precipitation over the North Pacific from 1984 1994 to 1995-2005 inferred from the Global Precipitation Climatology Project. Geophys. Res. Lett., 35, L13821, doi:10.1029/2008GL034668.

— - _ and R. Zhang, 2008b: Implementation of a two-moment bulk microphysics scheme to the WRF model to investigate aerosol-cloud interaction. J. Geophys. Res., 113, D15211, doi:10.1029/2007JD009361.

— - — K.-H. Lee, Y. Diao, and R. Zhang, 2009: Impacts of aerosols on the development and precipitation of a mesoscale squall line. J. Geophys. Res., 114, D17205, doi:10.1029/ 2008JD011581.

Li, J., K. von Salzen, Y. Peng, H. Zhang, and X.-Z. Liang, 2013: Evaluation of black carbon semi-direct radiative effect in a climate model. J. Geophys. Res. Atmos., 118, 4715-4728, doi:10.1002/jgrd.50327.

Li, Z. Q., F. Niu, J. W. Fan, Y. G. Liu, D. Rosenfeld, and Y. N. Ding, 2011: Long-term impacts of aerosols on the vertical development of clouds and precipitation. Nat. Geosci., 4, 888894, doi:10.1038/ngeo1313.

Lim, K.-S. S., and S.-Y. Hong, 2010: Development of an effective double-moment cloud microphysics scheme with prognostic cloud condensation nuclei (CCN) for weather and climate models. Mon. Wea. Rev., 138, 1587-1612, doi:10.1175/2009MWR2968.1.

Lin, J. C., T. Matsui, R. A. Pielke, and C. Kummerow, 2006: Effects of biomass-burning-derived aerosols on precipitation and 
clouds in the Amazon Basin: A satellite-based empirical study. J. Geophys. Res., 111, D19204, doi:10.1029/2005JD006884.

Lindeman, J. D., Z. Boybeyi, and I. Gultepe, 2011: An examination of the aerosol semi-direct effect for a polluted case of the ISDAC field campaign. J. Geophys. Res., 116, D00T10, doi:10.1029/ 2011JD015649.

Liu, Y., and P. H. Daum, 2002: Anthropogenica erosols: Indirect warming effect from dispersion forcing. Nature, 419, 580-581, doi:10.1038/419580a.

Lu, C. S., S. J. Niu, Y. G. Liu, and A. M. Vogelmann, 2013: Empirical relationship between entrainment rate and microphysics in cumulus clouds. Geophys. Res. Lett., 40, 2333-2338, doi:10.1002/grl.50445.

Matsui, T., H. Masunaga, S. M. Kreidenweis, R. A. Pielke, W.-K. Tao, M. Chin, and Y. J. Kaufman, 2006: Satellite-based assessment of marine low cloud variability associated with aerosol, atmospheric stability, and the diurnal cycle. J. Geophys. Res., 111, D17204, doi:10.1029/2005JD006097.

McFarquhar, G. M., S. Platnick, L. Di Girolamo, H. K. Wang, G. Wind, and G. Y. Zhao, 2004: Trade wind cumuli statistics in clean and polluted air over the Indian Ocean from in situ and remote sensing measurements. Geophys. Res. Lett., 31, L21105, doi:10.1029/2004GL020412.

Milbrandt, J. A., and M. K. Yau, 2005: A multimoment bulk microphysics parameterization. Part II: A proposed threemoment closure and scheme description. J. Atmos. Sci., 62 , 3065-3081, doi:10.1175/JAS3535.1.

Mlawer, E. J., S. J. Taubman, P. D. Brown, M. J. Iacono, and S. A. Clough, 1997: Radiative transfer for inhomogeneous atmospheres: RRTM, a validated correlated-k model for the longwave. J. Geophys. Res., 102, 16663-16 682, doi:10.1029/97JD00237.

Morrison, H., 2012: On the robustness of aerosol effects on an idealized supercell storm simulated with a cloud systemresolving model. Atmos. Chem. Phys., 12, 7689-7705, doi:10.5194/acp-12-7689-2012.

Nesbitt, S. W., R. Y. Zhang, and R. E. Orville, 2000: Seasonal and global $\mathrm{NO}_{X}$ production by lightning estimated from the Optical Transient Detector (OTD). Tellus, 52B, 1206-1215, doi:10.1034/j.1600-0889.2000.01121.x.

Orville, R. E., and Coauthors, 2001: Enhancement of cloud-toground lightning over Houston, Texas. Geophys. Res. Lett., 28 , 2597-2600, doi:10.1029/2001GL012990.

Peng, J., and Coauthors, 2016: Markedly enhanced absorption and direct radiative forcing of black carbon under polluted urban environments. Proc. Natl. Acad. Sci. USA, 113, 4266-4271, doi:10.1073/pnas.1602310113.

Pruppacher, H. R., and J. D. Klett, 1996: Microphysics of Clouds and Precipitation. 2nd ed. Springer, 976 pp.

Sakaeda, N., R. Wood, and P. J. Rasch, 2011: Direct and semidirect aerosol effects of southern African biomass burning aerosol J. Geophys. Res., 116, D12205, doi:10.1029/2010JD015540.

Saleeby, S. M., W. Berg, S. van den Heever, and T. L'Ecuyer, 2010: Impact of cloud-nucleating aerosols in cloud-resolving model simulations of warm-rain precipitation in the East China Sea. J. Atmos. Sci., 67, 3916-3930, doi:10.1175/2010JAS3528.1.

— S. R. Herbener, S. C. van den Heever, and T. L'Ecuyer, 2015: Impacts of cloud droplet-nucleating aerosols on shallow tropical convection. J. Atmos. Sci., 72, 1369-1385, doi:10.1175/ JAS-D-14-0153.1.

Seifert, A., and K. D. Beheng, 2006: A two-moment cloud microphysics parameterization for mixed-phase clouds. Part 2: Maritime vs. continental deep convective storms. Meteor. Atmos. Phys., 92, 67-82, doi:10.1007/s00703-005-0113-3.
Seigel, R. B., 2014: Shallow cumulus mixing and subcloud-layer responses to variations in aerosol loading. J. Atmos. Sci., 71, 2581-2603, doi:10.1175/JAS-D-13-0352.1.

Shi, J. J., and Coauthors, 2014: Implementation of an aerosolcloud-microphysics-radiation coupling into the NASA unified WRF: Simulation results for the 6-7 August 2006 AMMA special observing period. Quart. J. Roy. Meteor. Soc., 140, 2158-2175, doi:10.1002/qj.2286.

Small, J. D., P. Y. Chuang, G. Feingold, and H. Jiang, 2009: Can aerosol decrease cloud lifetime? Geophys. Res. Lett., 36, L16806, doi:10.1029/2009GL038888.

_ J. H. Jiang, H. Su, and C. X. Zhai, 2011: Relationship between aerosol and cloud fraction over Australia. Geophys. Res. Lett., 38, L23802, doi:10.1029/2011GL049404.

Storer, R. L., S. C. van den Heever, and G. L. Stephens, 2010: Modeling aerosol impacts on convective storms in different environments. J. Atmos. Sci., 67, 3904-3915, doi:10.1175/ 2010JAS3363.1.

Tao, W.-K., and T. Matsui, 2015: Cloud-system resolving modeling and aerosols. Encyclopedia of Atmospheric Sciences, 2nd ed. Elsevier, 222-231, doi:10.1016/B978-0-12-382225-3.00511-9.

_ X. Xi, A. Khain, T. Matsui, S. Lang, and J. Simpson, 2007: Role of atmospheric aerosol concentration on deep convective precipitation: Cloud-resolving model simulations. J. Geophys. Res., 112, D24S18, doi:10.1029/2007JD008728.

_ J.-P. Chen, Z. Li, C. Wang, and C. Zhang, 2012: Impact of aerosols on convective clouds and precipitation. Rev. Geophys., 50, RG2001, doi:10.1029/2011RG000369.

Tie, X. X., S. Madronich, S. Walters, R. Y. Zhang, P. Rasch, and W. Collins, 2003: Effect of clouds on photolysis and oxidants in the troposphere. J. Geophys. Res., 108, 4642, doi:10.1029/ 2003JD003659.

Turner, D. D., S. A. Clough, J. C. Lijegren, E. E. Clothiaux, K. E. Cady-Pereira, and K. L. Gaustad, 2007: Retrieving liquid water path and precipitable water vapor from the Atmospheric Radiation Measurement (ARM) microwave radiometers. IEEE Trans. Geosci. Remote Sens., 45, 3680-3690, doi:10.1109/TGRS.2007.903703.

Twomey, S., 1977: The influence of pollution on the shortwave albedo of clouds. J. Atmos. Sci., 34, 1149-1152, doi:10.1175/ 1520-0469(1977)034<1149:TIOPOT>2.0.CO;2.

van den Heever, S. C., G. G. Carrió, W. R. Cotton, P. J. DeMott, and A. J. Prenni, 2006: Impacts of nucleating aerosol on Florida storms. Part I: Mesoscale simulations. J. Atmos. Sci., 63, 1752-1775, doi:10.1175/JAS3713.1.

_ G. L. Stephens, and N. B. Wood, 2011: Aerosol indirect effects on tropical convection characteristics under conditions of radiative-convective equilibrium. J. Atmos. Sci., 68, 699-718, doi:10.1175/2010JAS3603.1.

Vogelmann, A. M., and Coauthors, 2012: RACORO extended-term aircraft observations of boundary layer clouds. Bull. Amer. Meteor. Soc., 93, 861-878, doi:10.1175/ BAMS-D-11-00189.1.

Wang, S., Q. Wang, and G. Feingold, 2003: Turbulence, condensation, and liquid water transport in numerically simulated nonprecipitating stratocumulus clouds. J. Atmos. Sci., 60, 262-278, doi:10.1175/1520-0469(2003)060<0262: TCALWT $>2.0 . \mathrm{CO} ; 2$.

Wang, Y., Q. Wan, W. Meng, F. Liao, H. Tan, and R. Zhang, 2011: Long-term impacts of aerosols on precipitation and lightning over the Pearl River Delta megacity area in China. Atmos. Chem. Phys., 11, 12421-12436, doi:10.5194/ acp-11-12421-2011. 
J. W. Fan, R. Y. Zhang, L. R. Leung, and C. Franklin, 2013a: Improving bulk microphysics parameterizations in simulations of aerosol effects. J. Geophys. Res. Atmos., 118, 5361-5379, doi:10.1002/jgrd.50432.

—_, A. Khalizov, M. Levy, and R. Y. Zhang, 2013b: New directions: Light absorbing aerosols and their atmospheric impacts. Atmos. Environ., 81, 713-715, doi:10.1016/ j.atmosenv.2013.09.034.

— , K.-H. Lee, Y. Lin, M. Levy, and R. Zhang, 2014a: Distinct effects of anthropogenic aerosols on tropical cyclones. Nat. Climate Change, 4, 368-373, doi:10.1038/nclimate2144.

__ and Coauthors, 2014b: Assessing the effects of anthropogenic aerosols on Pacific storm track using a multiscale global climate model. Proc. Natl. Acad. Sci. USA, 111, 6894-6899, doi:10.1073/pnas.1403364111.

- R. Y. Zhang, and R. Saravanan, 2014c: Asian pollution climatically modulates mid-latitude cyclones following hierarchical modelling and observational analysis. Nat. Commun., 5, 3098, doi:10.1038/ncomms4098.

Werner, F., and Coauthors, 2014: Twomey effect observed from collocated microphysical and remote sensing measurements over shallow cumulus. J. Geophys. Res. Atmos., 119, 15341545, doi:10.1002/2013JD020131.

Wilcox, E. M., 2010: Stratocumulus cloud thickening beneath layers of absorbing smoke aerosol. Atmos. Chem. Phys., 10, 11 769-11 777, doi:10.5194/acp-10-11769-2010.

Williams, E. R., R. Zhang, and J. Rydock, 1991: Mixed-phase microphysics and cloud electrification. J. Atmos. Sci., 48, 2195-2203, doi:10.1175/1520-0469(1991)048<2195: MPMACE $>2.0 . \mathrm{CO} ; 2$.

Wood, R., 2012: Stratocumulus clouds. Mon. Wea. Rev., 140, 23732423, doi:10.1175/MWR-D-11-00121.1.

Wu, G., and Coauthors, 2016: Advances in studying interactions between aerosols and monsoon in China. Sci. China Earth Sci., 59, 1-16, doi:10.1007/s11430-015-5198-z.

Xue, H., and G. Feingold, 2006: Large-eddy simulations of trade wind cumuli: Investigation of aerosol indirect effects. J. Atmos. Sci., 63, 1605-1622, doi:10.1175/JAS3706.1.
,-- , and B. Stevens, 2008: Aerosol effects on clouds, precipitation, and the organization of shallow cumulus convection. J. Atmos. Sci., 65, 392-406, doi:10.1175/2007JAS2428.1.

Yamaguchi, T., G. Feingold, J. Kazil, and A. McComiskey, 2015: Stratocumulus to cumulus transition in the presence of elevated smoke layers. Geophys. Res. Lett., 42, 10 478-10 485, doi:10.1002/2015GL066544.

Yang, Q., and Coauthors, 2012: Impact of natural and anthropogenic aerosols on stratocumulus and precipitation in the Southeast Pacific: A regional modelling study using WRF-Chem. Atmos. Chem. Phys., 12, 8777-8796, doi:10.5194/ acp-12-8777-2012.

Yuan, T. L., Z. Q. Li, R. Y. Zhang, and J. W. Fan, 2008: Increase of cloud droplet size with aerosol optical depth: An observation and modeling study. J. Geophys. Res., 113, D04201, doi:10.1029/ 2006JC004067.

Zhang, D., W. F. Lei, and R. Y. Zhang, 2002: Mechanism of OH formation from ozonolysis of isoprene: Kinetics and product yields. Chem. Phys. Lett., 358, 171-179, doi:10.1016/ S0009-2614(02)00260-9.

Zhang, M. H., and Coauthors, 2005: Comparing clouds and their seasonal variations in 10 atmospheric general circulation models with satellite measurements. J. Geophys. Res., 110, D15S02, doi:10.1029/2004JD005021.

Zhang, R., G. Li, J. Fan, D. L. Wu, and M. J. Molina, 2007: Intensification of Pacific storm track linked to Asian pollution. Proc. Natl. Acad. Sci. USA, 104, 5295-5299, doi:10.1073/pnas.0700618104.

_ A. F. Khalizov, J. Pagels, D. Zhang, H. Xue, and P. H. McMurry, 2008: Variability in morphology, hygroscopicity, and optical properties of soot aerosols during atmospheric processing. Proc. Natl. Acad. Sci. USA, 105, 10291-10296, doi:10.1073/pnas.0804860105.

_ and Coauthors, 2015: Formation of urban fine particulate matter. Chem. Rev., 115, 3803-3855, doi:10.1021/acs.chemrev.5b00067.

Zhao, J., R. Y. Zhang, K. Misawa, and K. Shibuya, 2005: Experimental product study of the $\mathrm{OH}$-initiated oxidation of $m$-xylene. J. Photochem. Photobiol., 176A, 199-207, doi:10.1016/ j.jphotochem.2005.07.013. 